\title{
Progenesis as an intrinsic factor of ecological opportunity in a polyphenic amphibian
}

\author{
Benjamin Lejeune $^{1,2}$, Lucie Bissey ${ }^{1}$, Emilie Alexia Didaskalou ${ }^{1}$, Nicolas Sturaro ${ }^{2}$, Gilles \\ Lepoint $^{2}$ and Mathieu Denoël ${ }^{1}$
}

\begin{abstract}
${ }^{1}$ Laboratory of Ecology and Conservation of Amphibians (LECA), Freshwater and OCeanic science Unit of reSearch (FOCUS), University of Liège, Belgium

${ }^{2}$ Laboratory of Oceanology, Freshwater and OCeanic science Unit of reSearch (FOCUS), University of Liège, Belgium
\end{abstract}

Corresponding author: Benjamin Lejeune

Email: Benjamin.Lejeune@uliege.be

\section{ORCID ID:}

Benjamin Lejeune: 0000-0001-6881-8931

Nicolas Sturaro: 0000-0002-7225-0880

Gilles Lepoint: 0000-0003-4375-0357

Mathieu Denoël: 0000-0002-3586-8323

\begin{abstract}
1. Paedomorphosis, a developmental heterochrony involving the retention of larval traits at the adult stage, is considered a major evolutionary process because it can generate phenotypic variation without requiring genetic modifications. Two main processes underlie paedomorphosis: neoteny, a slowdown of somatic development, and progenesis, a precocious maturation associated to body size reduction. Being essentially a truncation of ontogeny, progenesis has often been deemed an evolutionary dead-end with advantages attributed to precocious reproduction or small body size required in specific environmental contexts (e.g. parasitism, interstitial life), but there is a lack of studies on the immediate ecological consequences of progenesis.

2. Because body size is a key factor determining trophic ecology in animals, we hypothesized that progenesis might intrinsically promote ecological opportunity via body size reduction (i.e. 'the trophic advantage of progenesis' hypothesis). We tested this hypothesis in facultatively progenetic palmate newts (Lissotriton helveticus) using stable isotope niche modelling and diet reconstruction in conjunction with traditional stomach content analyses and body condition assessment.

3. We show that not only did progenetic individuals occupy a different trophic niche than metamorphic individuals in all populations, but the smaller they were compared to metamorphs due to progenesis, the more different they were in terms of trophic ecology, with no negative effect on their body condition.
\end{abstract}


4. Altogether, the results suggest that via body size reduction, progenesis may generally act as an intrinsic factor of ecological opportunity, allowing the use of existing but previously unavailable resources, even in habitats where seemingly little opportunity exists. We argue that beyond the classically recognized fitness advantages of progenetic development, this process may also generally bring an immediate trophic advantage via body size reduction, which would have important implications to understand the evolution and adaptiveness of this process in many different taxa, from marine meiofauna to primates.

\section{KEYWORDS}

developmental novelty, diet, facultative paedomorphosis, heterochrony, key innovation, niche differentiation, stable isotope analysis, trophic polyphenism.

\section{Introduction}

Paedomorphosis is a heterochrony, which means a process involving change in the rate or timing of development of the somatic versus sexual organs or tissues, allowing individuals to retain larval or juvenile traits at the adult stage (Gould, 1977). The importance of paedomorphosis in the evolution of animals is well documented and observable both in fossil and living species records in multiple invertebrate and vertebrate taxa, including humans (Gao \& Shubin, 2001; Long, 1990; McKinney \& McNamara, 1991; McNamara, 1997; McNamara, 2012). Paedomorphosis is considered a major evolutionary process in animals, acting at both micro- and macroevolutionary scales, because it does not require genetic modifications to rapidly provide a large array of new traits upon which natural selection can act (Bonett \& Blair, 2017; Fabre et al., 2020; Gould, 1977; Long, 1990; McKinney \& McNamara, 1991; McNamara, 2012). This is especially true for the variety of organisms with complex life-cycles involving metamorphosis (Laudet, 2011), where paedomorphosis can lead to radically different phenotypes (Fabre et al., 2020; McKinney \& McNamara, 1991). Paedomorphosis can result from two main distinct heterochronic processes: neoteny, consisting in a retardation of somatic development, and progenesis, consisting in an acceleration of sexual development and therefore a precocious sexual maturation and reproduction at smaller body size (Gould, 1977; McKinney \& McNamara, 1991). As Gould (1977) discussed, while neoteny has long been considered as a key process increasing the evolutionary potential of a lineage and providing an escape from specialization, progenesis, being essentially a truncation of ontogeny, has often been deemed an evolutionary dead-end leading to over-specialization such as in parasites. Yet, there is evidence that progenesis could also give rise to adaptive radiation such as in ammonoids and echinoids (Korn, 1995; McNamara, 1997). Although macroevolutionary studies draw inferences about the importance of the environment on the evolution of progenetic organisms, research on a shallow time-scale is essential to ascertain its potential immediate ecological advantages. Hypotheses about the immediate significance of progenesis have mainly revolved around the advantages of a precocious reproduction in r-selected regimes, including a reduction in generation time and higher fitness, potentially ultimately favouring speciation (Gould, 1977; Hanken \& Wake, 1993; Kon \& Yoshino, 2002; Ryan \& Semlitsch, 1998). To a lesser extent, 
the occurrence of progenesis was also associated to specific environmental contexts that may require a small body size (e.g. in parasites [Lefebvre \& Poulin 2005], or in meiofauna for a better mobility through the sediment and interstitial habitat colonization [Snyder \& Bretsky 1971; Gould 1977; Westheide 1987; McKinney \& McNamara 1991; Struck et al. 2015]). Yet it is well recognized that body size is also an important determinant of the trophic niche of species and its change can provide competitive advantages or give access to unused resources (Cohen, Pimm, Yodzis, \& Saldaña, 1993; Wilson, 1975; Woodward \& Hildrew, 2002). While competitive advantages are evident in the case of an increase in body size, the evolution towards small body size has been suggested to act as a morphological novelty allowing the exploitation of existing resources in a novel way and the colonization of new adaptive zones (i.e. intrinsic factor of ecological opportunity; Simpson 1944; Hanken \& Wake 1993; Frédérich et al. 2017). However, there is a need for empirical evidence on shallow time-scale, and such hypothesis has, to our knowledge, never been developed or tested in the case of progenesis.

Polyphenisms involving progenesis are excellent models to study the immediate ecological consequences of progenesis because they can produce alternative size-dimorphic morphologies that share a common evolutionary history and live in similar or even identical habitats during a part of their life (Denoël, Drapeau, \& Winandy, 2019b; Kalezić, Cvetković, Djorović, \& Džukić, 1996; Lefebvre \& Poulin, 2005; West-Eberhard, 2003). Facultative progenesis is frequent in palmate newt (Lissotriton helveticus) populations of the Larzac Plateau (France), where both phenotypes co-occur in small ponds, particularly in spring during the strictly aquatic reproductive period (Denoël et al., 2019b; Denoël \& Ficetola, 2015; Denoël, Ivanović, Džukić, \& Kalezić, 2009). These populations represent an ideal natural system in which to study immediate significance of progenesis on an ecological time-scale and shed light on what might constitute the adaptive basis of this polyphenism in newts living in shallow ponds.

In newts and salamanders, disruption of metamorphosis, which is the ancestral trait, by paedomorphosis is frequent (Bonett \& Blair, 2017; Fabre et al., 2020). Facultatively paedomorphic populations of newts (whether neotenic or progenetic) are composed of two phenotypes that coexist and feed in the aquatic habitat during the shared reproductive period: paedomorphs (adults retaining larval gills), which are strictly aquatic, and metamorphs (fully metamorphosed adults), which are able to disperse on land after the reproductive aquatic period (Denoël, 2005b; Mathiron, Lena, Baouch, \& Denoël, 2017). In newts, neoteny is associated with stable environmental conditions or lower temperature and productivity, such as in alpine newts living in high altitudinal lakes, where both metamorphs and neotenics have similar body length. Conversely, progenesis can be found in less stable, more productive and shallow habitats, where it leads to earlier maturity and significant body size reduction in progenetics compared to metamorphs (Denoël \& Joly, 2000), as is the case for palmate newts living in ponds in mid-elevated lands (Denoël et al., 2019b; Denoël \& Ficetola, 2015; Denoël et al., 2009).

Irrespective of the underlying developmental trajectories of paedomorphosis (i.e. neoteny or progenesis), the evolution and persistence of paedomorphosis and metamorphosis in newts and salamanders has been classically viewed as an adaptation to or a product of 
environmental constraints allowing phenotypes to fit with the stability of their environment (Denoël, Joly, \& Whiteman, 2005; Whiteman, 1994; Wilbur \& Collins, 1973). Paedomorphosis can be advantageous to avoid life in detrimental terrestrial habitats or when aquatic conditions are favourable (the 'paedomorph advantage' hypothesis; Wilbur \& Collins 1973), but it can also emerge as a default strategy under poor aquatic conditions ('best of a bad lot' hypothesis; Whiteman 1994). Both models were supported by ecological modelling and mesocosm experiments in different species (Denoël \& Ficetola, 2014; Semlitsch, 1987; Whiteman et al., 2012). Progenesis, more specifically, can also provide an advantage by allowing an early reproduction, but with a lower breeding output (Denoël et al., 2019b; Denoël \& Joly, 2000). By contrast, metamorphosis always remains adaptive in the case of deterioration of the aquatic habitat (e.g. drying that induces larvae to become metamorphs) and in terms of dispersal (Denoël et al., 2005; Denoël, Whiteman, \& Wissinger, 2007; Mathiron et al., 2017; Semlitsch, 1987; Whiteman, 1994). As it is a polyphenism, metamorphs, which are typically the only dispersers in newts, can therefore give birth to future progenetics following population crashes, then reconstituting facultatively progenetic populations (Denoël \& Winandy, 2015). Neoteny, more specifically, has also been associated to modification of feeding mechanisms in aquatic habitats (Denoël, 2004; Lauder \& Shaffer, 1993) and shown to promote resource partitioning along the littoral-pelagic axis in facultatively neotenic alpine newts living in a deep lake, by expanding the trophic niche of the population towards pelagic resources that were underused by metamorphs (Denoël \& Joly, 2001; Lejeune, Sturaro, Lepoint, \& Denoël, 2018). Although this trophic advantage may account for the long-term persistence of this polyphenism in neotenic populations living in deep lakes that are devoid of competitors (i.e. high potential for niche vacancy), it is still unclear whether progenesis might provide a similar trophic advantage, especially in habitats of considerably lower spatial heterogeneity, that lack a true pelagic zone such as shallow semi-permanent ponds, where progenetic populations are found. Indeed, strong habitat heterogeneity associated to increased ecosystem size, such as the existence of littoral and pelagic zones in lakes, has long been proposed as a key factor in the evolution and maintenance of trophic polyphenisms in teleost fish (Nosil \& Reimchen, 2005; Recknagel, Hooker, Adams, \& Elmer, 2017; Smith \& Skúlason, 1996; Wimberger, 1994) or in amphibians (Denoël \& Joly, 2001; Lejeune et al., 2018). On the one hand, previous research suggested some space and food partitioning between phenotypes in ponds, but much less obvious than in neotenic populations living in deep lakes (Denoël, 2005a; Denoël \& Andreone, 2003). On the other hand, progenesis was shown to lead to an important size dimorphism between the two phenotypes in these populations (Denoël et al., 2009), but the effect of body size reduction due to progenesis on the trophic niche of newts has never been addressed.

Here, we hypothesized that trophic niche differentiation via body size reduction might constitute an immediate ecological advantage of progenesis, as an intrinsic factor of ecological opportunity, which lessens intraspecific competition (sensu Simpson 1944). To test this 'trophic advantage of progenesis' hypothesis, we studied facultatively progenetic palmate newts from four populations and assessed trophic niche use of the two phenotypes by analysing stable isotope and stomach content data in relation to the magnitude of body size reduction of progenetic individuals compared to metamorphs within each population, and accounting for 


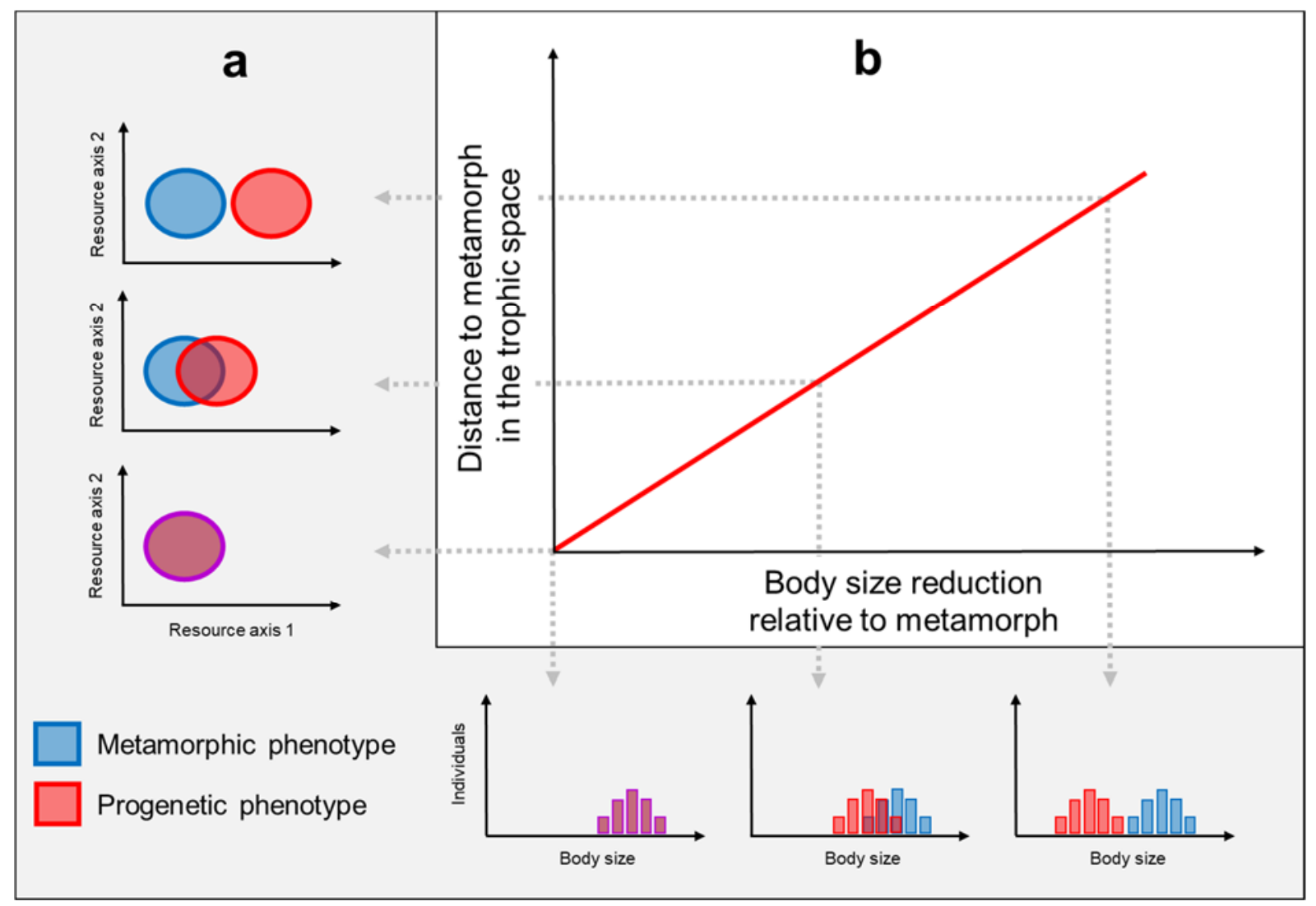

Figure 1: The 'trophic advantage of progenesis' hypothesis.

(a) Progenesis allows for niche differentiation in the trophic space and the exploitation of resources that are underused by the metamorphic (or ancestral) phenotype. (b) The more progenetic the individuals, and therefore the smaller they are compared to metamorphs, the more distant they are to metamorphic individuals in the trophic space, eventually until complete population niche partitioning.

pond depth, newt density and prey diversity as extrinsic factors of ecological opportunity. We coupled trophic niche analysis to body condition assessment to address potential differences in the success of progenesis vs. metamorphosis. Stomach content analysis can be used to quantify prey use at a relatively high taxonomic resolution and is considered the most reliable method for direct dietary assessment in amphibians (Costa et al., 2014). By contrast, stable isotope ratios of a consumer tissue are time and space integrative tracers of the assimilated diet that can provide indirect dietary information and be used to infer resource use at a broader scale, as well as isotopic niche use (proxy for trophic niche) at the population level (Jackson, Inger, Parnell, \& Bearhop, 2011; Newsome, Martinez del Rio, Bearhop, \& Phillips, 2007). Yet, comparison of stable isotope values of consumers from different populations can be hampered by variation in isotope values of their resources across sites (Newsome et al., 2007), so that comparisons of isotopic niche parameters across sites may lead to erroneous interpretations if values are not corrected accordingly. As such, we propose an adaptation to the method developed for food web standardization by Fry and Davis (2015), which can be used to account for variation in stable isotope values of food resources when comparing isotopic niches of a single consumer species across different sites. Following the 'trophic advantage hypothesis of progenesis' illustrated in Figure 1, we predicted first that facultative progenesis would promote niche differentiation towards resources that are underused by the ancestral phenotype (metamorph), 
without negatively affecting newts body condition and despite low habitat heterogeneity associated to ecosystem size; therefore contributing to the long-term persistence of the polyphenism as a strategy to lessen intraspecific competition in such habitat (Denoël \& Ficetola, 2014; Denoël et al., 2005; Whiteman et al., 2012). This would involve trophic niche differentiation which could be either partial or complete between alternative phenotypes. Second, we predicted that the degree of trophic differentiation by progenesis would be positively influenced by the magnitude of body size reduction compared to the ancestral phenotype, both within and across populations, therefore constituting an intrinsic factor of ecological opportunity (sensu Simpson 1944) and providing an immediate ecological advantage of progenesis through body size reduction (Figure 1).

\section{Materials and methods}

\subsection{Study sites}

The study sites are located in Larzac (Occitanie, France), a limestone plateau with traditionally managed habitats. Four ponds of similar structure but varying dimensions were selected for this study (Figure S1 in Supporting Information). These ponds are man-made, generally permanent (i.e. no drying observed during the study period and the year before) and constitute the main habitat type of facultatively progenetic palmate newts, Lissotriton helveticus (Amphibia, Salamandridae) (Denoël, 2007; Gabrion, Sentein, \& Gabrion, 1977). Although the age of Larzac ponds is unknown, they are of ancient origin with some archives mentioning some of them during the $13^{\text {th }}$ century (Fages, 2004). All but one studied here were already present in aerial photographs (1950-1965) but from their construction they were likely built at much older times. The earliest known observation of paedomorphs in these ponds was in the early 1970s (Gabrion et al., 1977). The use of structurally similar ponds in the same landscape and altitude limits the impact of potential confounding environmental factors (e.g. climate, habitat structure) (Table S1). The minimum distance between the studied ponds is of $3.7 \mathrm{~km}$. Sampling was done in spring (late April to early June) during the reproductive period when both phenotypes coexist in the aquatic habitat.

\subsection{Sampling}

Newts of both phenotypes were captured in each pond by dip netting (exact sample size for each analysis are presented in Table S2). All paedomorphs have external gills and open gill slits, as opposed to fully metamorphosed adults. Both are adults identified as such by the presence of a developed cloaca, which is sexually dimorphic in both phenotypes of the studied species (Denoël, 2017). Individuals were anaesthetized in a bath of phenoxyethanol $(0.5 \mathrm{ml} / \mathrm{l})$ and then measured to the nearest $0.5 \mathrm{~mm}$ (snout-vent length, from the tip of the snout to the end of the cloaca) and weighted to the nearest $0.01 \mathrm{~g}$. Each newt was sampled for stomach content by stomach flushing (Joly, 1987) just after the anaesthesia and within $30 \mathrm{~min}$ to avoid prey digestion (Schabetsberger, 1994). Stomach contents were stored individually in $70 \%$ ethanol and later analysed in the laboratory. One skin sample of the caudal tail fin of each newt was selected to perform stable isotope analysis (Lejeune et al., 2018). Amphibian skin integrates diet information from 2-3 months before capture (Cloyed, Newsome, \& Eason, 2015), which 
in this case makes it the most suitable non-lethal tissue. This technique does not affect newts (Arntzen, Smithson, \& Oldham, 1999) and caudal fin can fully regrow over two months (B. Lejeune pers. obs.). All newts were kept in tanks filled with water from their original pond until they were completely awake before being released. Potential food sources of newts were collected in each pond (minimum $n$ per taxa $=5$ ) to run stable isotope analysis. Samples were taken in the different microhabitats and at different depths of ponds for each category of potential food sources to be as representative as possible of the existing isotopic variability in

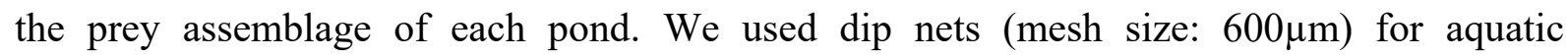
invertebrates and terrestrial prey drowning on the water surface and a tractable net for zooplankton (mesh size: $250 \mu \mathrm{m}$ ). Resource diversity of each pond was estimated from numerical abundance of prey in quadrats of $30 \times 30 \mathrm{~cm}(n=4$ per pond, mesh size $=600 \mu \mathrm{m})$. Finally, an index of adult newt density was estimated from standardized blind dip-netting sessions across ponds (Denoël \& Winandy, 2015), and expressed as individuals* $\mathrm{m}^{-2} * 2 \mathrm{~h}^{-1}$. During censuses, newts were kept in tanks filled with water from the pond and then counted and identified according to phenotype. The presence of individuals with empty stomach and difficulties to obtain isotope composition of some newts (too little caudal skin) explain the small difference in sample sizes among body size, stomach content and stable isotope analysis (see details in Table S2).

\subsection{Body size and body condition of newts}

Newts snout-vent length (SVL) and body weight were used to compute a body condition index (BC) calculated as the residuals of the regression of $1 n$-transformed body mass on lntransformed SVL (Denoël, Hervant, Schabetsberger, \& Joly, 2002; Jakob, Marshal, \& Uetz, 1996). Differences in SVL (Ln-transformed to meet homoscedasticity) and BC between phenotypes, sex and ponds were assessed using a three-way PERMANOVA based on Euclidean distances including the effects of phenotype, sex, pond and their interactions. Significant interaction terms were examined using PERMANOVA pairwise tests and Bonferroni correction of the $p$-value for multiple testing (Bonferroni, 1936). All PERMANOVA tests were computed with 9,999 permutations to assess significance of the results. Shannon (1948) index of invertebrates in quadrats of each pond was used as a measure of prey diversity and calculated following the equation: $H^{\prime}=-\Sigma p_{\mathrm{i}} \times \ln p_{\mathrm{i}}$, where $p_{\mathrm{i}}$ is the proportion of prey $i$ relative to the total number of prey in a given quadrat. Comparison of Shannon index among ponds were done using a one-way PERMANOVA based on Euclidean distances followed by PERMANOVA pairwise tests. Both tests were conducted using Monte Carlo approximation of the $p$-value and all PERMANOVA tests were conducted in PRIMER version 7 software (Clarke \& Gorley, 2006) and the PERMANOVA+ add-in (Anderson, Gorley, \& Clarke, 2008).

\subsection{Stable isotope data processing and rescaling}

Samples were oven-dried at $60^{\circ} \mathrm{C}$ for $72 \mathrm{~h}$ (Binder, Tubingen, Germany) and subsequently ground into a homogeneous powder. Stable isotope ratios of carbon and nitrogen were measured using an isotope ratio mass spectrometer (Isoprime 100; Isoprime, Cheadle Hulme, UK) coupled in continuous flow to an elemental analyser (Vario MICRO cube; Elementar, 
Langensbold, Germany) and conventionally expressed as $\delta$ values in \%o (see all details of the analytical procedure in Appendix S1). The $\delta^{13} \mathrm{C}$ isotope ratio of a specific tissue sample can be influenced by the lipid content of that tissue. To rule out potential confounding effect of this factor in subsequent stable isotope analyses we assessed variation in the elemental $\mathrm{C}: \mathrm{N}$ ratio (proxy for lipid content) of the tail fin samples according to individual SVL, phenotype and sex across ponds (linear mixed model testing for all effects and interactions and including pond as a random factor) and tested for an effect of $\mathrm{C}: \mathrm{N}$ ratio on $\delta^{13} \mathrm{C}$ across all individuals (linear model). There was no significant variation of $\mathrm{C}: \mathrm{N}$ ratio according to any variables (population mean $\pm \mathrm{SD}$ value $=3.4 \pm 0.2$, see detailed model results in Table S3) and no effect of $\mathrm{C}: \mathrm{N}$ ratio on $\delta^{13} \mathrm{C}$ variation across individuals $(t=-1.00, p=0.316)$. To account for prey isotope variation across sites arising from non-trophic processes (e.g. baseline shifts) when comparing isotopic niches of newts, we adapted a food web rescaling method based on modified $Z$-scores (Fry \& Davis, 2015). This method was adapted by rescaling stable isotope data of newts by calculating modified $Z$-scores using mean and standard deviation of their prey community at each site (details on the rescaling method are provided in Appendix S1). This way, isotope values of consumers are normalized according to prey isotope variation across sites and centered according to the local prey community so that shifts in isotope values or variation in niche size of newts can be directly interpretable as trophic changes, while removing non-trophic variation that would hamper across sites comparisons. As in the original method (Fry \& Davis, 2015), rescaled stable isotope values conserve units near the original ones (\% deviation from international standards) but are expressed using a $\Delta$ notation to avoid confounding them with original $\delta$ values.

\subsection{Isotopic niche differences and the effect of progenesis}

We used Stable Isotope Bayesian Ellipses in R (Jackson et al., 2011) to generate bivariate standard ellipses representing core isotopic niches of newts in each population, using the package SIBER version 2.1.0 in R version 3.3.1. To account for sample size differences, areas of the ellipses associated with each group (Standard Ellipse Area B; SEAB) were computed using Bayesian inference (MCMC parameters: 2 chains, 200,000 iterations, 10,000 burn-ins, thins $=50$, and using an inverted wishart prior; Jackson et al. 2011). Isotopic niches of each population were calculated and compared across sites at the phenotype level to test for niche differentiation. This allowed for particularly robust estimations of SEAв $(n>30)$, therefore independent of sample size (Jackson et al., 2011). Three additional metrics were calculated based on posterior distributions of standard ellipse parameters of both phenotypes and their overlap: the Euclidean distance between the centroids of paedomorphs and metamorphs isotopic niche $\left(\mathrm{CD}_{\mathrm{B}}\right)$, the percentage of shared niche space between the two phenotypes ( $\mathrm{SNS}_{\mathrm{B}}$ ), both used as measures of niche differentiation, and the percent contribution of progenesis to the isotopic niche of the population $\left(\mathrm{PC}_{\mathrm{B}}\right)$, used as a measure of niche expansion through facultative progenesis (Lejeune et al., 2018). $\mathrm{SNS}_{\mathrm{B}}$ was calculated following the equation: $\mathrm{SNS}_{\mathrm{B}}=100$ * Overlap $_{(\mathrm{PM})} /\left(\mathrm{SEAB}_{\mathrm{P}} \mathrm{P}\right)+\mathrm{SEA}_{\mathrm{B}(\mathrm{M})}-$ Overlap$\left._{(\mathrm{PM})}\right)$. $\mathrm{PC}_{\mathrm{B}}$ was calculated following the equation: $\mathrm{PC}_{\mathrm{B}}=100 *\left(\mathrm{SEA}_{\mathrm{B}(\mathrm{P})}-\right.$ Overlap $\left._{(\mathrm{PM})}\right) /\left(\mathrm{SEA}_{\mathrm{B}(\mathrm{P})}+\mathrm{SEA}_{\mathrm{B}(\mathrm{M})}-\right.$ Overlap $\left._{(\mathrm{PM})}\right)$, where $\mathrm{P}=$ paedomorphs and $\mathrm{M}=$ metamorphs. Differences in isotopic niche parameters ( $\mathrm{SEAB}, \mathrm{CDB}$, 
$\mathrm{SNS}_{\mathrm{B}}$ and $\mathrm{PC}_{\mathrm{B}}$ ) were tested using direct pairwise comparisons by deriving probabilities of differences from their posterior distributions and were expressed as percentages.

We performed linear mixed models to test for the effects of phenotype, sex and SVL on $\Delta^{13} \mathrm{C}$ and $\Delta^{15} \mathrm{~N}$ values of newts, considering pond as a random factor. Then, to specifically assess the potential role of body size reduction of progenetic compared to metamorphic newts in niche differentiation, we calculated two metrics for each progenetic individual within each sex: body size reduction compared to the mean body size of metamorphs in each population (BSr, proxy for progenesis), as well as the Euclidean distance separating them from the centroid of metamorphs niche in the isospace in each population (ISO-DIST, proxy for trophic differentiation). Both metrics were calculated within each sex to control for the potential confounding effect of sexual size dimorphism. We tested the effect of BSr on ISO-DIST while controlling for pond depth using a linear model considering the effects of BSr, sex, pond depth and their interactions on ISO-DIST. Since pond dimensions simultaneously increased with decreasing newt density, it was not possible to decipher between these two factors in this study (Pearson correlation $=-0.97, t_{2}=-5.725, p=0.029$ ), but the effect of increasing pond depth can be more generally interpreted as an increase in extrinsic ecological opportunity, and was interpreted in this way. Finally, we tested whether the body condition of progenetics was further influenced by the degree of niche differentiation with metamorphs (ISO-DIST), which could potentially indicate a cost or benefit of progenesis associated to the degree of niche differentiation. We used a linear mixed model testing for the effects of ISO-DIST, sex and their interaction on $\mathrm{BC}$ of progenetics, while considering pond identity as a random factor. Linear models including mixed effect models were performed in R version 3.5.1 (R Core Team, 2018) using the package nlme (Pinheiro, Bates, DebRoy, Sarkar, \& R Core Team, 2018).

\subsection{Diet and stable isotope mixing model analysis}

Diet differences between phenotypes were assessed using both stomach content and stable isotope data. Prey obtained from stomach flushing were identified and counted under a stereoscopic microscope (Zeiss Stemi 2000-C; Carl Zeiss, Jena, Germany). Diet differences between phenotypes and sexes within each population were assessed using a two-way PERMANOVA based on Bray-Curtis distances calculated from proportions of prey per stomach (Anderson, 2001; Anderson \& Walsh, 2013), performed on each population separately. Proportions of prey per stomach were square root transformed to meet the assumption of homogeneity of multivariate dispersion and down-weight the impact of overabundant but smaller prey compared to less abundant but larger prey in the calculation of dissimilarities (e.g. zooplankton compared to macroinvertebrates). Homogeneity of multivariate dispersion was tested prior to all analyses using permutational analysis of multivariate dispersion (PERMDISP). Subsequent similarity percentage (SIMPER) analysis was performed to assess the average percent contribution of each prey type to significant differences identified by PERMANOVA (Clarke, 1993). PERMANOVA, PERMDISP, SIMPER and PERMANOVA pairwise tests were performed in PRIMER version 7 software (Clarke \& Gorley, 2006) and the PERMANOVA+ add-in (Anderson et al., 2008). All tests were computed with 9,999 permutations to assess significance of the results. 
Stable isotope Bayesian mixing models were computed using 'MixSIAR' ver. 3.1.7 (Stock \& Semmens, 2016) to establish the contribution of food sources from different origins to the isotopic composition of newts within each pond, incorporating diet proportions from stomach content data as prior information. Different food sources identified in stomach contents were combined a priori in the models according to their isotopic similarity to improve discrimination ability. Food sources from the final models were then combined a posteriori in two categories: ' $\mathrm{T}-\mathrm{OW}-\mathrm{A}$ ' = terrestrial, open water and amphibian prey, and ' $\mathrm{B}-\mathrm{V}$ ' = benthic and vegetation associated invertebrates. 'Terrestrial' food sources are terrestrial insects drowning on the water surface. 'Open water' food sources are pelagic invertebrates (Chaoboridae and zooplankton) and active predatory swimmers (Notonectidae). 'Amphibian' food sources are eggs or larvae. 'Benthic and vegetation associated invertebrates' are Baetidae, Chironomidae, Coenagrionidae, Coleoptera larvae, Corixidae, Libellulidae and Ostracoda. Trophic enrichment factors (TEFs) for amphibian skin were applied: $2.3 \pm 0.5(\%)$ for $\delta^{15} \mathrm{~N}$ and $0.1 \pm 0.4$ (\%) for $\delta^{13} \mathrm{C}$ (Cloyed et al., 2015), as they were successfully used in a previous study on newts trophic ecology (Lejeune et al., 2018). All details on the parameterization of mixing models are given in Appendix S1, with a comparison of informed and uninformed model results in Table B and final model parameters in Table C.

\section{Results}

3.1 Newt populations and ponds characteristics

Adult newt abundance decreased with increasing pond dimensions, with a total of 462, 221, 219 and 120 adult newts in pond A, B, C and D, from the smallest to the largest pond, respectively. The derived index of adult newt abundance in each pond were 4.3, 2.5, 1.4 and 0.3 individual $\mathrm{m}^{-2} 2 \mathrm{~h}^{-1}$, respectively (Table S1). All ponds contained both paedomorphic and metamorphic phenotypes of palmate newts (Figure $2 a$ and figure $2 b$ ). Proportions of paedomorphs were lower in populations $\mathrm{A}$ and $\mathrm{C}$ (15\% and $23 \%$, respectively), compared to populations $\mathrm{B}$ and D (66\% and $86 \%$, respectively). Paedomorphs were significantly smaller than metamorphs in all populations but the magnitude of this difference varied across populations, with paedomorphs of pond $\mathrm{B}$ being significantly the smallest compared to the three other populations (Figure $2 c$ ), as revealed by PERMANOVA indicating $p<0.001$ for 'Phenotype' (Pseudo- $F_{1,373}=772.56$ ), 'Pond' (Pseudo- $F_{3,373}=72.943$ ) and 'Phenotype $\mathrm{x}$ Pond' interaction (Pseudo- $F_{3,373}=58.16$; Table S4), with subsequent pairwise tests indicating $p<$ 0.001 for all pairwise phenotype differences within each pond (Table S5). Males were significantly smaller than females in all populations (Pseudo- $F_{1,373}=192.35, p<0.001$; Table S4). Progenetics had a higher body condition (BC) than metamorphs in pond A only (Figure $2 d$ ), as revealed by PERMANOVA showing $p<0.001$ for 'Phenotype' (Pseudo- $F_{1,373}=$ 19.628), 'Pond' (Pseudo- $F_{3,373}=40.606$ ) and 'Phenotype $\mathrm{x}$ Pond' interaction (Pseudo- $F_{3,373}=$ 7.702; Table S4) but with subsequent pairwise tests indicating significant phenotype differences only within pond A $\left(t_{91}=5.847, p<0.001\right.$; Table S5). Body condition (BC) was significantly higher in females than males in all populations (Pseudo- $F_{1,371}=4.237, p=0.044$; Table S4). Prey diversity $\left(H^{\prime}\right)$ differed significantly across ponds (Pseudo- $F_{3,12}=7.153, p=0.007$ ). 
PERMANOVA pairwise tests revealed that this was driven by a higher $H^{\prime}$ in the largest pond $\mathrm{D}$ compared to the two smallest ponds $\mathrm{A}$ and $\mathrm{B}(t=5.607, p=0.008$ and $t=5.991, p=0.007$, respectively; Table S6).

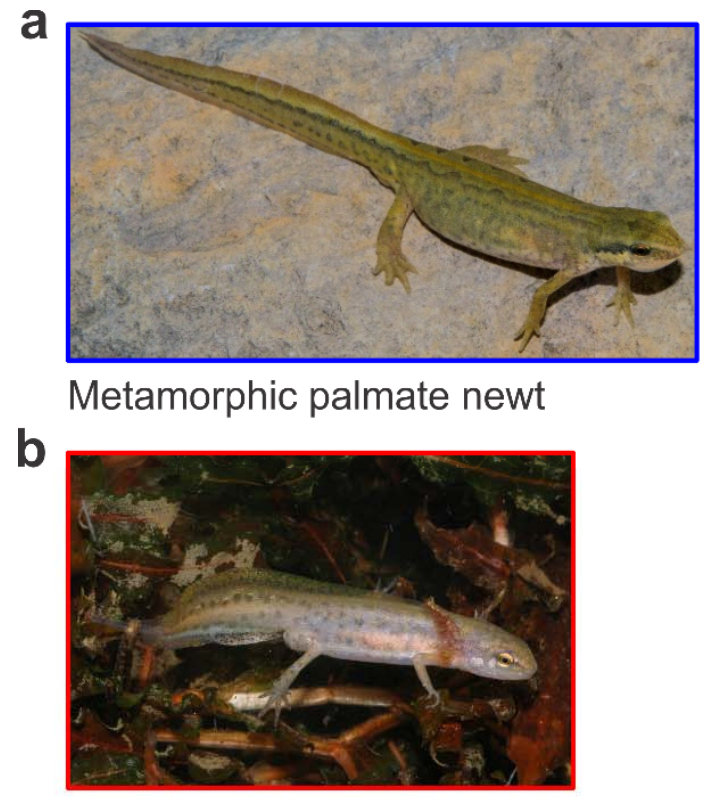

Progenetic palmate newt
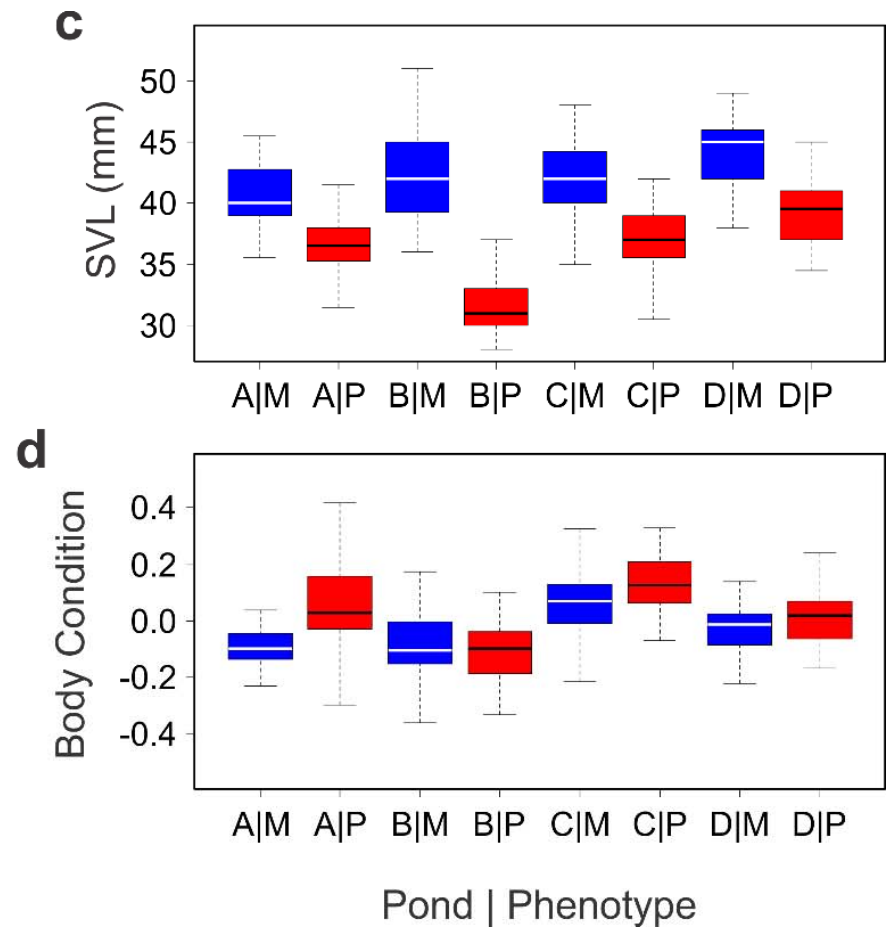

Figure 2: Snout-vent length and body condition of metamorphic and progenetic paedomorphic palmate newts (Lissotriton helveticus).

The figured specimens are a metamorphic female (a) and a paedomorphic male (b) from pond A, Larzac, France. (c) Snout-vent length (SVL) and (d) Body condition index (BC) of metamorphic (M; in blue) and paedomorphic (P; in red) palmate newts sampled from each pond (A, B, C and $\mathrm{D}$, from the shallowest to the deepest pond, respectively). Boxplots represent median (25-75\%) $\pm 1.5 \mathrm{IQR}$ (interquartile range). Photo credits: (a) B. Lejeune and (b) M. Denoël.

\subsection{Isotopic niche differences between progenetic and metamorphic newts}

Stable isotope analysis revealed a similar pattern of niche differentiation between progenetic and metamorphic newts across populations (Figure $3 a$ ). Phenotype differences within each population were mainly visible along the $\Delta^{13} \mathrm{C}$ axis. In all ponds, metamorphs were more depleted in ${ }^{13} \mathrm{C}$ compared to paedomorphs. Centroid distance $\left(\mathrm{CD}_{\mathrm{B}}\right)$ between paedomorphs and metamorphs niche was the highest in the most progenetic population $\mathrm{B}$ (Figure $3 b$; Table $\mathrm{S} 7$ ), with $100 \%$ posterior probability compared to the three others (Table S8). Likewise, the percent contribution of paedomorphosis $\left(\mathrm{PC}_{\mathrm{B}}\right)$ to the population isotopic niche width were the highest in both the most progenetic population (pond $\mathrm{B}: \mathrm{PC}_{\mathrm{B}}=51 \%, \mathrm{CI}_{95}=38-64$ ) and in the largest pond (pond $\mathrm{D}: \mathrm{PC}_{\mathrm{B}}=57 \%, \mathrm{CI}_{95}=46-67$; Figure $3 c$; Table $\mathrm{S} 7$ ), with high posterior probabilities compared to the other population (80-99\% posterior probabilities; Table S8). Linear mixed models of the effects of phenotype, sex and snout-vent length (SVL) on $\Delta^{13} \mathrm{C}$ and $\Delta^{15} \mathrm{~N}$ values of newts revealed that there was no global effect of SVL on $\Delta^{13} \mathrm{C}$ or $\Delta^{15} \mathrm{~N}$ values of newts. However, phenotype (paedomorphs vs. metamorph) was a significant predictor of $\Delta^{13} \mathrm{C}\left(t_{320}=\right.$ 
4.438, $p<0.001)$ and $\Delta^{15} \mathrm{~N}$ values of newts $\left(t_{320}=2.609, p=0.01\right)$ across ponds (Table S9), with paedomorphs having higher $\Delta^{13} \mathrm{C}$ and $\Delta^{15} \mathrm{~N}$ values than metamorphs in all populations (Figure 3a; Table S7), and there was a significant Phenotype $\times$ SVL interaction in both cases, revealing an increase in both $\Delta^{13} \mathrm{C}$ and $\Delta^{15} \mathrm{~N}$ values with decreasing SVL within paedomorphs only ( $t_{320}=-3.78, p<0.001$ and $t_{320}=-0.132, p=0.015$, respectively; Figure $3 d$ and $e$; Table S9). There was no significant effect of sex on $\Delta^{13} \mathrm{C}$ and $\Delta^{15} \mathrm{~N}$ values of newts $\left(t_{320}=-1.022, p\right.$ $=0.308$ and $t_{320}=0.660, p=0.510$, respectively), or Phenotype $\times$ Sex and SVL $\times$ Phenotype $\times$ Sex interactions (all $p>0.05$ ). Finally, there was no overlap between the isotopic niches of paedomorphs and metamorphs, except a partial overlap in pond $\mathrm{C}\left(\mathrm{SNS}_{\mathrm{B}}=35 \%, \mathrm{CI}_{95}=22-48\right.$; Table S7). In this population, paedomorphs were more depleted in ${ }^{13} \mathrm{C}$ than in the other populations, bringing their niche closer to that of metamorphs, while they also had the largest isotopic niche $\left(\mathrm{SEA}_{\mathrm{B}}\right)$ of all populations. There was no general pattern of isotopic niche size $\left(\mathrm{SEA}_{\mathrm{B}}\right)$ difference between the two phenotypes across populations (Figure S2; Table S7).

\subsection{Effect of body size reduction due to progenesis on isotopic niche differentiation}

Linear model testing the effect of body size reduction of paedomorphs compared to metamorphs of the same population due to progenesis (BSr), sex and pond depth (proxy for extrinsic ecological opportunity) on their isotopic distance to metamorphs of the same population (ISODIST) revealed a significant effect of BSr on ISO-DIST $\left(t_{166}=6.612, p<0.001\right)$, but with a $\mathrm{BSr} \times$ Pond depth interaction $\left(t_{166}=-2.869, p=0.005\right.$; Figure 4; Table S10). This indicated that the isotope distance to metamorphs increased with body size reduction in progenetic individuals, but that the magnitude of this effect decreased with increasing pond dimension (Figure $4 b)$. There was no global effect of Pond depth on ISO-DIST $\left(t_{166}=1.647, p=0.101\right)$. There was an additional significant effect of sex on ISO-DIST $\left(t_{166}=4.287, p<0.001\right)$ and a significant Sex $\times$ Pond depth interaction $\left(t_{166}=-3.067, p=0.003\right)$ indicating that there was an effect of sex on the isotopic distance to metamorphs that decreased with increasing pond dimension (Figure $4 b)$. Finally, a BSr $\times$ Sex interaction $\left(t_{166}=-2.276, p=0.024\right)$ indicated that the effect of increased isotopic distance to metamorphs with body size reduction in progenetic individuals was lower in males than in females (Figure $4 a$ ). Linear mixed model revealed no significant effect of the degree of niche differentiation of progenetics compared to metamorphs (ISO-DIST: $\left.t_{166}=-1.543, p=0.125\right)$ or Sex $\times$ ISO-DIST interaction $\left(t_{166}=1.477, p=0.142\right)$ on body condition $(\mathrm{BC})$ of progenetics, but a global effect of Sex on BC $\left(t_{166}=-2.015, p=\right.$ 0.046). 


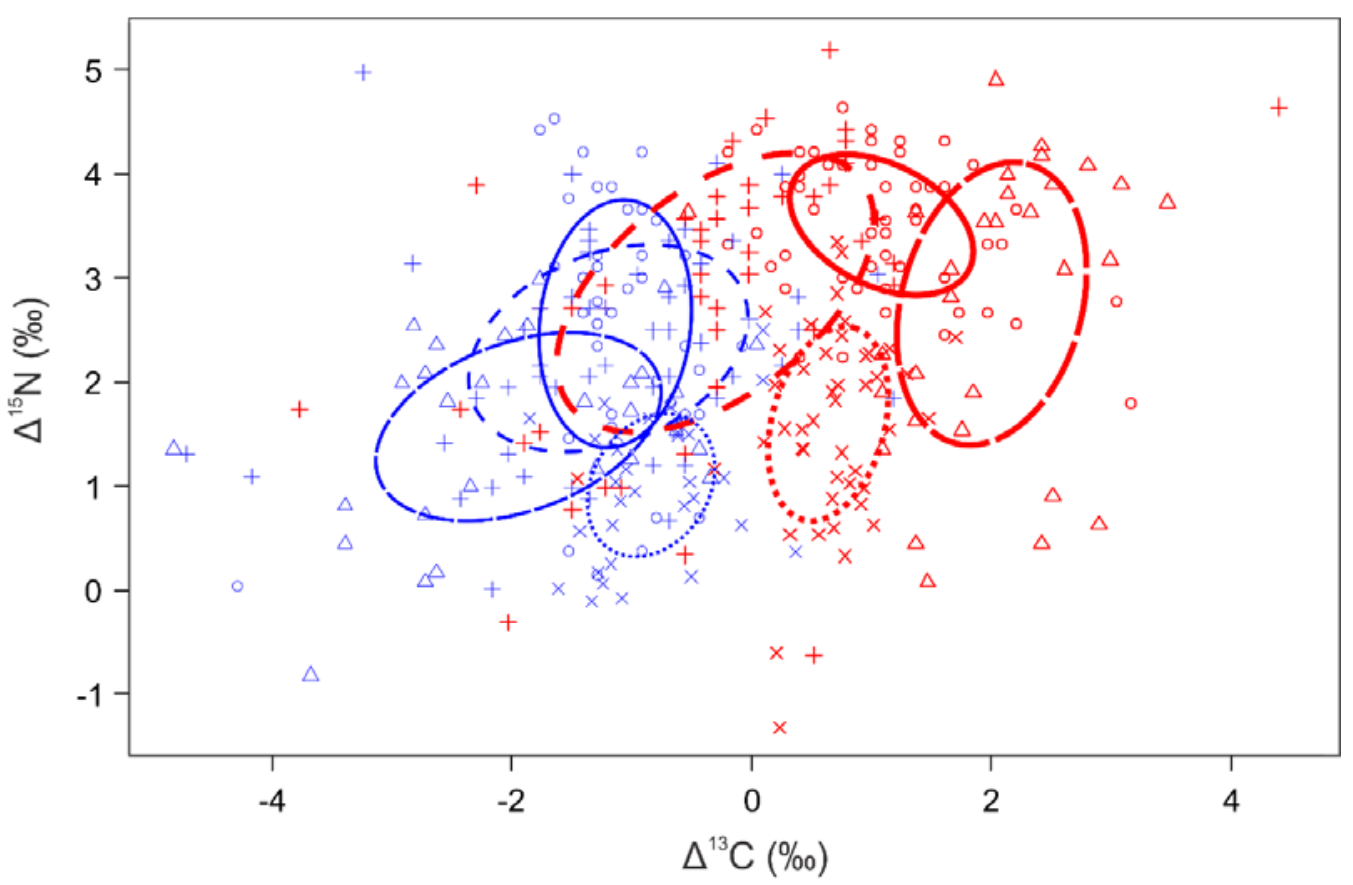

b

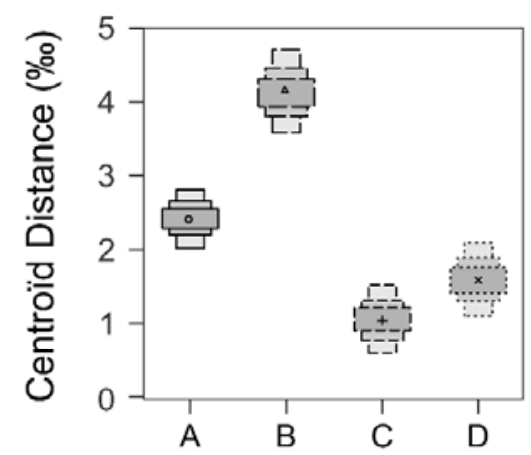

C

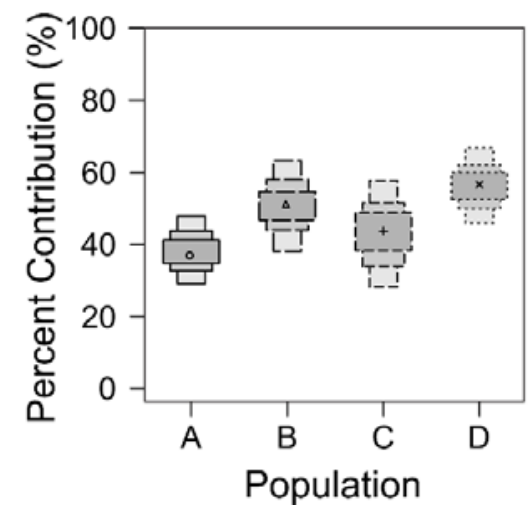

d

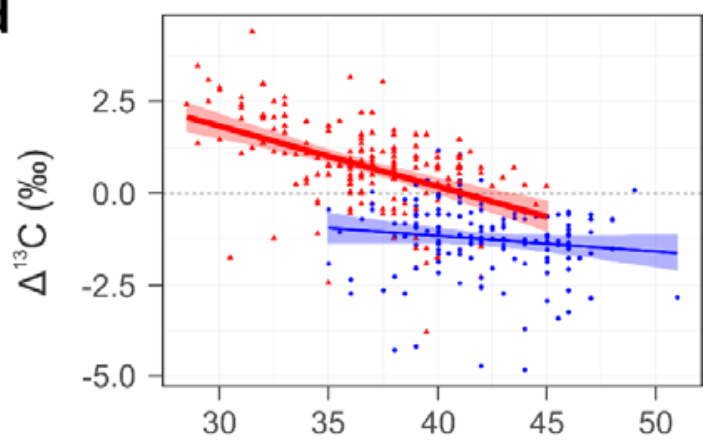

e

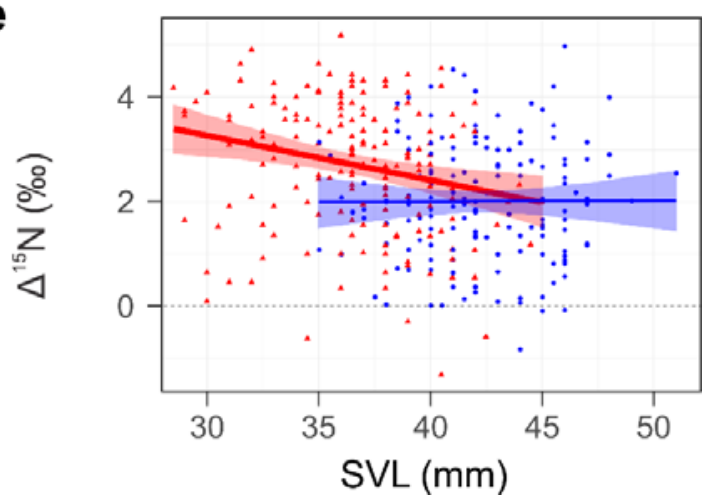

Figure 3: Analysis of isotopic niche differences between paedomorphic and metamorphic newts.

(a) Stable isotope bi-plot illustrating the isotopic niche of paedomorphic (thick red lines) and metamorphic (thin blue lines) palmate newts across the four ponds. Symbols and line types legend: Pond $\mathrm{A}=$ circles, full lines; Pond $\mathrm{B}=$ triangles, short space dashed lines; Pond $\mathrm{C}=$ plus symbols, medium space dashed lines; Pond $\mathrm{D}=$ crosses, dotted lines. (b) Bayesian estimates of the centroid distance $\left(\mathrm{CD}_{\mathrm{B}}\right)$ between paedomorphs and metamorphs standard ellipses area and (c) the percent contribution of paedomorphosis to the total niche width of the population $\left(\mathrm{PC}_{\mathrm{B}}\right)$ in population $\mathrm{A}, \mathrm{B}, \mathrm{C}$ and $\mathrm{D}$ of palmate newts. Symbols indicate modes of posterior distributions and grey rectangles encompass $50 \%, 75 \%$ and $95 \%$ credible intervals of the posterior density of each parameter, from the darkest to the lightest, respectively. Symbols and line types around boxplots correspond to those of Figure $3 a$. (d) Fixed effect of snout-vent length (SVL) of newts on $\Delta^{13} \mathrm{C}$ values and (e) on $\Delta^{15} \mathrm{~N}$ values of metamorphic and paedomorphic palmate newts across ponds, with $95 \%$ confidence interval. Full blue line and circles $=$ Metamorphs. Dashed red lines and triangles $=$ Paedomorphs. 


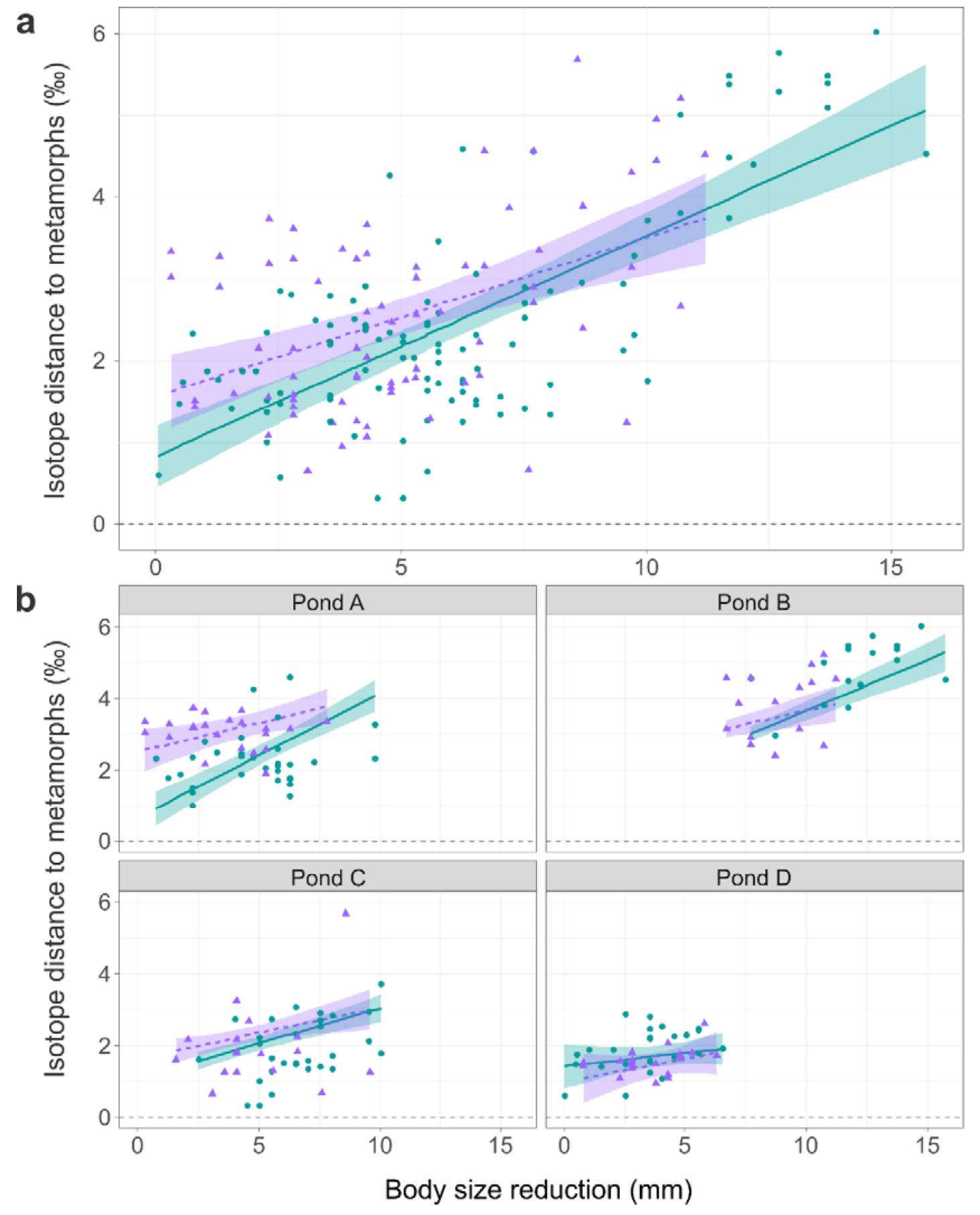

Figure 4: Effect of body size reduction (BSr) of paedomorphs compared to metamorphs due to progenesis on the isotopic distance to metamorphs (ISO-DIST).

Effect of BSr (mm, measured as snout-vent length) on ISO-DIST is presented (a) within each sex across populations, and (b) in each population separately. Ponds A - D, from the shallowest to the deepest (see Table S1). Paedomorphic females: full green line and circles. Paedomorphic males: dashed violet line and triangles. Error bands represent $95 \%$ confidence interval. 

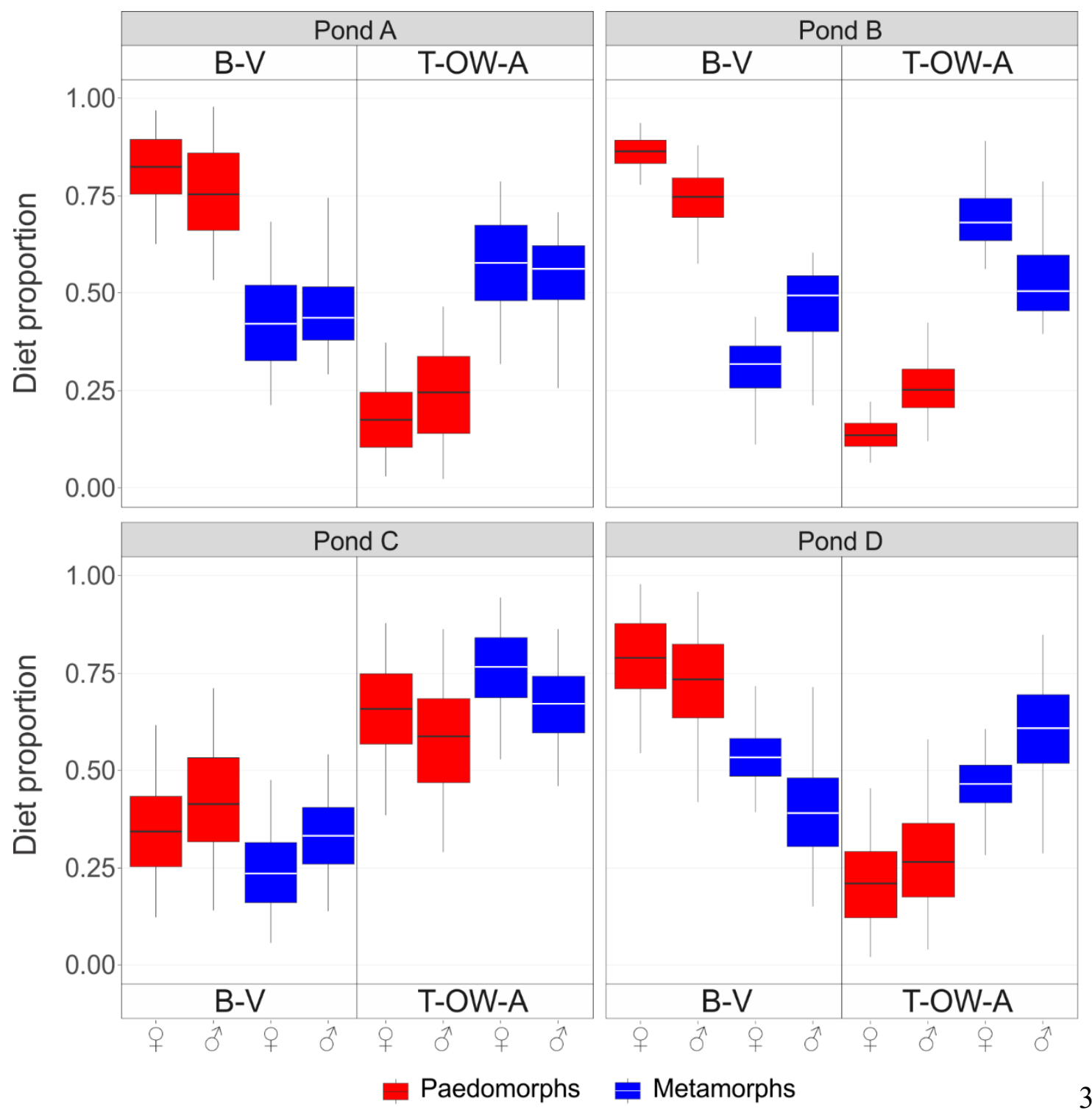

Figure 5: Stable isotope mixing models depicting the assimilated diet of paedomorphic (red) and metamorphic (blue) newts of both sexes in each pond.

Food source contributions to the isotopic composition of newts were combined a posteriori into two categories: ' $\mathrm{B}-\mathrm{V}$ ' = benthic and vegetation associated invertebrates, and ' $\mathrm{T}-\mathrm{OW}-\mathrm{A}$ ' $=$ terrestrial, open water and amphibian prey. Contributions are presented as boxplots delimiting 50\% credible intervals (boxes) and 95\% credible intervals (whiskers) around the mode of the posterior distributions. See Table S13 for model solutions before a posteriori grouping and Table B in Appendix S1 for a comparison of these results with results from uninformed models.

3.4 Diet characterization of progenetic and metamorphic newts based on stomach contents and stable isotope analysis

PERMANOVA on prey abundance in newts' stomach revealed a significant difference $(p<$ 0.05 ) between the trophic niche of paedomorphs and metamorphs in all populations (Table $\mathrm{S} 11$ ), with an additional significant sex effect in the two largest ponds $\mathrm{C}$ and $\mathrm{D}$ (pseudo- $F_{1,105}$ $=4.292, p=0.002$ and pseudo- $F_{1,85}=3.592, p=0.004$, respectively). In pond $\mathrm{B}$, a significant phenotype $\times$ sex interaction (pseudo- $F_{1,45}=2.113, p=0.040$ ) indicated that diet differences 
between paedomorphs and metamorphs were mainly driven by differences between females ( $t_{30}$ $=2.680, p<0.001)$ and not males $\left(t_{15}=1.187, p=0.172\right)$, but the number of males without empty stomach in that pond was low $(n=6)$. Subsequent SIMPER analysis revealed a similar pattern of differences in foraging habits of paedomorphs and metamorphs across populations (Table S12). Paedomorphs generally consumed more taxa associated to the aquatic vegetation or benthic habitat (e.g. Baetidae, Corixidae, Coleoptera larvae, Ostracoda and Chironomidae) than metamorphs, accounting for most of the dissimilarities observed between the two phenotypes across ponds (Cumulative percentage of contribution to the Bray-Curtis dissimilarity $>80 \%$ ). Metamorphs consumed more zooplankton and Chaoboridae (which they capture while standing on top of the aquatic vegetation or in the littoral zones, usually not actively swimming in open waters; B. Lejeune pers. obs.) as well as amphibian eggs and tadpoles. In pond $\mathrm{C}$, both phenotypes relied more on zooplankton than in the three other ponds. Sex differences found in the two largest ponds were mainly due to females consuming more amphibian eggs or tadpoles and larger invertebrates such as Zygoptera or terrestrial invertebrates.

Stable isotope mixing models revealed important differences between phenotypes in terms of aquatic $v s$. terrestrial trophic linkage across populations that were not evident based on stomach content analysis alone (Figure 5; Table B in Appendix S1). On the long-term (i.e. as shown by stable isotopes), paedomorphs were more reliant on aquatic resources linked to benthic microhabitats and the aquatic vegetation ('B-V'). Metamorphs were more reliant on terrestrial subsidies, invertebrates found in open waters and other amphibian eggs or tadpoles ('T-OW-A'), explaining their important depletion in ${ }^{13} \mathrm{C}$ (Figure $3 a$; Table S7). Concordant with patterns of isotopic niche differences, mixing models showed that the partial overlap between the niches of paedomorphs and metamorphs in pond $\mathrm{C}$ was due to an increase in the reliance of paedomorphs on prey typically representative of metamorphs diet (Figure 5; Table $\mathrm{S} 13)$, hence their more depleted ${ }^{13} \mathrm{C}$ values compared to paedomorphs of other ponds.

\section{Discussion}

4.1 Niche differentiation via body size reduction as an immediate ecological advantage of progenesis

Because the mechanism underlying paedomorphosis is progenesis (i.e. earlier maturation) in the studied populations of palmate newts, paedomorphs were significantly smaller than metamorphs in all populations. Following our hypothesis (Figure 1), not only did paedomorphs use a different niche than metamorphs in all populations, but the smaller they were due to progenesis, the more distant they were from metamorphs isotopic niche, and this effect was visible both within and across populations. There was no difference in body condition between phenotypes across populations, and no effect of the degree of niche differentiation of progenetics compared to metamorphs, on their body condition. This indicates that there is no cost associated with the observed niche differentiation through body size reduction, in terms of body condition. Body condition of progenetics was even higher than that of metamorphs in the smallest pond A. This is in line with theory on the links between body size and trophic niche, 
and the significance of changes in body size as a way to colonize new adaptive peaks and escape intraspecific competition (Frédérich et al., 2017; Hanken \& Wake, 1993; Simpson, 1944; Wilson, 1975). Therefore, we showed empirical evidence that beyond generally hypothesized fitness advantages of progenetic development for organisms living in unpredictable environments such as an earlier reproduction and the ability to quickly reconstitute population size in-between episodes of environmental stress (Gould 1977; McKinney \& McNamara 1991; Denoël \& Joly 2000; but see also Denoël et al., 2019 for reproductive costs due to progenesis in newts), this process may also bring an immediate ecological advantage in terms of niche differentiation via body size reduction. Given the importance of the influence of body size on the trophic niche of species (Cohen et al., 1993; Wilson, 1975; Woodward \& Hildrew, 2002), the ecological consequences of progenesis may potentially always carry a trophic component. Therefore, we suggest that trophic niche differentiation via body size reduction may be relevant to the evolution and adaptiveness of progenesis in the many different taxa where it occurred, from marine meiofauna to primates (Gould, 1977; McKinney \& McNamara, 1991; McNamara, 2012), as it could globally allow the generation of new opportunities and lessen resource competition with the ancestral phenotype. We argue that this hypothesis should be considered and tested generally using time and space integrative modelling tools of the trophic niche such as stable isotopes (Newsome et al., 2007).

Here, we assessed the success of progenesis using a proxy of seasonal fitness. There could be other associated costs (e.g. metabolic or reproductive) to progenesis, or interactions with seasonal or yearly changes in environmental conditions that cannot be measured or addressed here. For example, drying of the pond could force a progenetic newt to metamorphose (see Mathiron et al. 2017), in which case the trophic advantage may only be temporary. Cases where progenetics might metamorphose later in life, would make this issue just as much one of ontogenetic niche shift (Werner \& Gilliam, 1984) as one of niche differentiation between lineages. While progenesis can be transitory in some populations under extreme weather conditions, progenetics may also never metamorphose in permanent ponds (Denoël, Drapeau, Oromi, \& Winandy, 2019a; Gabrion, 1976). In palmate newts, considering larger time-scales, the potential advantages of progenesis in terms of the exploitation of underused resources and earlier reproduction may be counter balanced by episodes of drought, favouring metamorphosis, and conditioning the long-term persistence of progenesis as a polyphenism in these populations (Oromi, Michaux, \& Denoël, 2016). Ultimately, only measures of lifetime fitness may allow to decipher between the different factors that may interact in complex ways to influence the success of alternative developmental strategies (Lackey et al., 2019), and identify all the potential costs of progenesis (see also Denoël et al., 2019a). Future research on facultative progenesis in this system should aim to address these remaining questions to precise the strength of the 'trophic advantage of progenesis' hypothesis along newts lifetime and its role in its success and the long-term persistence of the polyphenism.

\subsection{Progenesis as an intrinsic factor of ecological opportunity}

In this study, the relation between body size reduction of paedomorphs compared to metamorphs due to progenesis and niche differentiation was generalized across populations, 
but its strength varied according to sex (this will be discussed in the next subsection) and extrinsic factors of ecological opportunity (i.e. the increase in pond dimension and simultaneous decrease in newt density). Extrinsic factors of ecological opportunity did not impact the degree of niche differentiation between paedomorphs and metamorphs, but the magnitude of the effect of body size reduction on niche differentiation within paedomorphs increased with decreasing pond dimensions. The most progenetic population showed the highest degree of niche differentiation between phenotypes despite inhabiting one of the shallowest pond. These results not only suggest that niche differentiation by progenesis may not depend upon the existence of large spatial heterogeneity, but also that body size reduction may specifically further help resource partitioning when dealing with low extrinsic ecological opportunity as is the case in shallow and densely populated ponds. Thereby, body size reduction due to progenesis may allow a trophic advantage even in conditions classically deemed unfavourable to paedomorphosis in newts (i.e. shallow ponds with a higher risk of drying; Wilbur \& Collins 1973), and to the persistence of stable trophic polyphenisms (i.e. low habitat heterogeneity; Skulason \& Smith 1995). Indeed, the ability to exploit underused resources can lessen intraspecific competition and ultimately allow higher reproductive success, therefore accounting for the adaptiveness and long-term persistence of trophic polyphenisms in the same habitat (Bolnick, 2001; Denoël, Schabetsberger, \& Joly, 2004; Schmidt, Bertness, \& Rand, 2000). But such stable trophic polyphenisms are expected to be advantageous in conditions of high habitat heterogeneity (higher potential for niche availability and discordance; Skulason \& Smith 1995; Wellborn \& Langerhans 2015), as is the case with teleost and amphibian polyphenisms along the littoral-pelagic axis in lakes (Lejeune et al., 2018; Nosil \& Reimchen, 2005; Recknagel et al., 2017; Smith \& Skúlason, 1996; Wimberger, 1994). In crowded environments with limited spatial heterogeneity, such as ponds, alternative trophic behaviours or phenotypes may manifest in the form of competition-dependent alternatives that are of unequal profitability and provide an advantage of one phenotype over the other that may eventually exclude or eliminate the latter (West-Eberhard, 1989), such as in the case of carnivore and cannibalistic morphs (Levis, de la Serna Buzón, \& Pfennig, 2015; Pfennig, 1992) or facultative paedomorphosis in other amphibian species (Whiteman, Wissinger, \& Brown, 1996). In these cases, alternative trophic phenotypes typically strongly fluctuate in time or across different habitat patches that better match their preferences and where their competitor phenotype may be absent. Here, despite low spatial heterogeneity and the lack of a true pelagic zone in ponds, both stomach content and stable isotope results revealed consistent patterns of niche differentiation within the same aquatic habitat between progenetic and metamorphic palmate newts across populations. This trophic niche differentiation was driven by body size reduction of progenetics, not impeded by extrinsic factors of ecological opportunity and had no effect on the body condition of progenetics. In this sense progenesis may be considered a developmental novelty intrinsically generating ecological opportunity in newts (i.e. giving access to existing but unavailable resources; Simpson 1944; Moczek et al. 2011; Erwin 2015) via body size reduction. This reinforces the relevance of generally considering the trophic advantage potentially carried by progenesis to understand its evolution and adaptiveness in 
many different taxa and environmental conditions (Gould, 1977; McKinney \& McNamara, 1991; McNamara, 2012).

4.3 Implications for facultative paedomorphosis in newts and potential sex-specific costs Both stomach content and stable isotope results revealed consistent patterns of niche differentiation between progenetic and metamorphic palmate newts across populations. Paedomorphs were more reliant on prey associated with benthic microhabitats and the aquatic vegetation, while metamorphs were more reliant on amphibian eggs and tadpoles, and prey that are found in open water or near the water surface such as terrestrial prey, heteropterans and zooplankton. This is consistent with behavioural changes known to accompany facultative progenesis in ponds, i.e. an increase in time spent in shelters such as the aquatic vegetation by paedomorphs, while metamorphs spend more time out of shelters in shallower areas little or not covered by aquatic vegetation (Denoël, 2005a; Winandy, Colin, \& Denoël, 2016). The results provide evidence that this spatial segregation pattern could be directly linked to differences in feeding strategies of the two phenotypes and suggest that low habitat heterogeneity associated to ecosystem size does not impede niche differentiation. Further, the niche of metamorphs did not shift or expand towards that of paedomorphs when newt density was low and resource diversity high, but was rather stationary in the isospace across ponds. At the opposite, variation in the location and breadth of paedomorphs niche suggest that they may be more plastic and in some cases expand their niche towards that of metamorphs by relying more on metamorphs preferred resources. Altogether, this suggests that progenesis allows exploitation of a niche that is effectively underused by the ancestral morph in the pond ecosystem, and that facultative progenesis could therefore constitute an adaptive strategy to lessen intraspecific competition in populations living in ponds.

The patterns of resource partitioning observed in this study suggest that feeding strategies of paedomorphic newts may depend upon the underlying heterochronic process. Indeed, in facultatively neotenic populations of the alpine newt inhabiting oligotrophic alpine lakes, paedomorphs have been shown to specialize on small zooplankton captured in the water column (Denoël, 2004; Denoël \& Joly, 2001; Lejeune et al., 2018), what newts were not seen to do in the studied ponds (M. Denoël and B. Lejeune, pers. obs). Importantly, we argue that the highly depleted ${ }^{13} \mathrm{C}$ values of metamorphs and their higher reliance on terrestrial subsidies revealed by stable isotope mixing models in all ponds do not reflect a consumption of terrestrial prey on land, but terrestrial insects found drowning in the aquatic environment. Indeed, on the one hand, these results are concordant with documented behaviours of metamorphs actively hunting terrestrial prey at the water surface in ponds and lakes (Chacornac \& Joly, 1985; Denoël \& Joly, 2001; Denoël et al., 2004; Vignoli, Luiselli, \& Bologna, 2009) and palmate newts of these populations are not known to leave the pond during the reproductive period to feed (M. Denoël, pers. obs.). On the other hand, terrestrial reliance identified by stable isotope analysis may also be influenced by the consumption of aquatic heteropterans whose isotopic compositions were sometimes indiscernible from that of terrestrial insects and that may themselves feed directly on terrestrial prey. Nevertheless, terrestrial subsidies such as drowning 
insects may be important and yet often underlooked resources for aquatic predators in freshwater ecosystems (Francis \& Schindler, 2009).

A potential mechanism underlying trophic niche differentiation with reduced body size of paedomorphic newts would be that suction force (paedomorphs feed by unidirectional suction flow as opposed to a bidirectional flow in metamorphs; Lauder \& Reilly 1994) may further increase with a reduced mouth opening associated to progenesis. Although paedomorphs are gape-size limited and have been shown to be more efficient at capturing small prey such as zooplankton in the pelagic zone of lakes (Denoël, 2004; Denoël et al., 2004), in this particular ecological context, a higher suction force may allow progenetic newts to capture some benthic prey or unhook macroinvertebrates associated to the aquatic vegetation more efficiently, both of which constituted the main items in their diet. Similar benthic specialization associated to small body size have been described in teleosts (Frédérich, Lehanse, Vandewalle, \& Lepoint, 2010). Allometry of the feeding structures, as well as suction force were not measured in this study, but this hypothesis offers interesting study perspectives.

Finally, stable isotope analysis also revealed a lower effect of body size reduction on niche differentiation via progenesis within males than within females. This may constitute a sex-specific cost of progenesis (Denoël et al., 2019b; Lackey et al., 2019; Whiteman, 1997) concurring to explain the low occurrence of progenetic males in palmate newt populations of the Larzac Plateau (Denoël et al., 2019b; Mathiron et al., 2017). This effect would add to another disadvantage of progenetic male newts, which are less sexually active than coexisting metamorphic males (Denoël et al., 2019b). However, despite a lower effect of body size reduction on niche differentiation in males than in females, progenesis still clearly gives access to resources that are underused by the ancestral morph for both sexes and could therefore explain their persistence in natural populations. These results along those from lifetime analyses (Lackey et al., 2019) are essential to understand the complex sex-specific payoffs of polyphenisms.

\section{Conclusions}

Here we have formalized the 'trophic advantage of progenesis' hypothesis and tested its predictions in facultatively progenetic populations of palmate newts living in ponds. Altogether, the results suggest that via body size reduction, progenesis may generally act as an intrinsic factor of ecological opportunity, allowing for niche differentiation and expansion, even in habitats where seemingly little opportunity exists, without affecting body condition of newts. This would constitute an immediate trophic advantage of progenesis with potentially broad adaptive implications in many taxa that have evolved towards small body sizes via progenesis or currently express facultative progenesis. Regarding newts, we demonstrated that while progenesis may limit the access to terrestrial environment, it can also open new possibilities in the aquatic environment, and be advantageous as a trophic polyphenism to exploit underused resources, concurring to explain its long-term persistence in habitats classically deemed unfavourable to paedomorphosis (e.g. shallow ponds with a high risk of drying). However, other associated costs, or complex interactions with environmental conditions that could not be addressed in this study may influence the potential trophic advantage provided by progenesis. 
Ultimately, only repeated assessment of niche differentiation and measures of lifetime fitness may allow to fully characterize advantages and costs related to progenesis. We argue that the methods and study system used here provide a useful and integrative avenue to further address complex evolutionary hypotheses related to heterochrony that largely remain empirically untested, and that the 'trophic advantage of progenesis' hypothesis should be considered and tested generally.

Funding information: This research benefited from F.R.S.-FNRS (Fonds de la Recherche scientifque) grants J.0008.13, J.0112.16, and T.0070.19 and a Fonds Spéciaux pour la Recherche grant C15/63 (Univ. of Liège) to M. Denoël.

Acknowledgements: We thank the two anonymous reviewers for their constructive comments. We are grateful to N. Belleuvre, A. Glavet, L. Prats and E. Wielgus for field help; to N. Brahic, C. Petit, J.L. Soulié, and L. Soulier for allowing access to the ponds. M. Denoël and G. Lepoint are, respectively, a Research Director and a Research Associate of the F.R.S. - FNRS. B. Lejeune was a PhD student funded by Fonds pour la Formation à la Recherche dans l'Industrie et dans l'Agriculture (FRIA). N. Sturaro was a Research Logistic Collaborator of the F.R.S. - FNRS. The capture permit of newts was issued by Direction Générale de l'Environnement, de l'Aménagement et du Logement Languedoc Roussillon. All manipulations followed ethical standards. The ethical aspects of the protocol were approved by the Conseil National de la Conservation de la Nature (France).

Authors' contributions: BL, MD and GL conceived the ideas and designed the methodology; BL and MD collected samples in the field; BL, LB and EAD identified and analyzed prey diversity and stomach contents data. BL, NS and GL processed and analyzed stable isotope data; BL and MD led the writing of the manuscript and the data analyses. All authors contributed critically to the drafts and gave final approval for publication.

Data Accessibility: Raw data are provided in ORBi repository (http://hdl.handle.net/2268/251605).

\section{References}

Anderson, M. J. (2001). A new method for non-parametric multivariate analysis of variance. Austral Ecology, 26(1), 32-46. doi: 10.1111/j.1442-9993.2001.tb00081.x

Anderson, M. J., Gorley, R. N., \& Clarke, K. R. (2008). PERMANOVA+ for PRIMER: A guide to software and statistical methods. PRIMER-E, Plymouth, UK.

Anderson, M. J., \& Walsh, D. C. I. (2013). PERMANOVA, ANOSIM, and the Mantel test in the face of heterogeneous dispersions: What null hypothesis are you testing? Ecological Monographs, 83(4), 557-574. doi: 10.1890/12-2010.1

Arntzen, A. J. W., Smithson, A., \& Oldham, R. S. (1999). Marking and tissue sampling effects on body condition and survival in the newt Triturus cristatus. Journal of Herpetology, 33(4), 567-576. doi: $10.2307 / 1565573$

Bolnick, D. I. (2001). Intraspecific competition favours niche width expansion in Drosophila melanogaster. Nature, 410(6827), 463-466. doi: 10.1038/35068555

Bonett, R. M., \& Blair, A. L. (2017). Evidence for complex life cycle constraints on salamander body 
form diversification. Proceedings of the National Academy of Sciences of the USA, 114, 99369941. doi: 10.1073/pnas.1703877114

Bonferroni, C. E. (1936). Teoria statistica delle classi e calcolo delle probabilità. Pubblicazioni Del R Istituto Superiore Di Scienze Economiche e Commerciali Di Firenze. doi: 10.4135/9781412961288.n455

Chacornac, J. M., \& Joly, P. (1985). Activité prédatrice du triton alpestre (Triturus alpestris) dans un lac alpin (2125 m, Alpes françaises). Acta Oecologica, 6, 93-103.

Clarke, K. R. (1993). Non-parametric multivariate analyses of changes in community structure. Australian Journal of Ecology, 18(1988), 117-143. doi: 10.1111/j.1442-9993.1993.tb00438.x

Clarke, K. R., \& Gorley, R. N. (2006). PRIMER v6: User Manual/Tutorial. PRIMER-E, Plymouth, UK.

Cloyed, C. S., Newsome, S. D., \& Eason, P. K. (2015). Trophic discrimination factors and incorporation rates of carbon- and nitrogen-stable isotopes in adult green frogs, Lithobates clamitans. Physiological and Biochemical Zoology, 88(5), 576-585. doi: 10.1086/682576

Cohen, J. E., Pimm, S. L., Yodzis, P., \& Saldaña, J. (1993). Body sizes of animal predators and animal prey in food webs. Journal of Animal Ecology, 62(1), 67-78. doi: 10.2307/5483

Costa, A., Salvidio, S., Posillico, M., Altea, T., Matteucci, G., \& Romano, A. (2014). What goes in does not come out: Different non-lethal dietary methods give contradictory interpretation of prey selectivity in amphibians. Amphibia-Reptilia, 35(2), 255-262. doi: 10.1163/15685381-00002944

Denoël, M. (2004). Feeding performance in heterochronic alpine newts is consistent with trophic niche and maintenance of polymorphism. Ethology, 110(2), 127-136. doi: 10.1111/j.14390310.2003.00958.x

Denoël, M. (2005a). Habitat partitioning in facultatively paedomorphic populations of palmate newts Triturus helveticus. Ambio, 34(6), 476-477. doi: 10.1579/0044-7447-34.6.476

Denoël, M. (2005b). Persistance et dispersion d'une population introduite de triton alpestre (Triturus alpestris) dans les causses du Larzac (sud de la France). Revue d'Ecologie (La Terre et La Vie), 60(2), 139-148.

Denoël, M. (2007). Priority areas of intraspecific diversity: Larzac, a global hotspot for facultative paedomorphosis in amphibians. Animal Conservation, 10(1), 110-116. doi: 10.1111/j.14691795.2006.00081.x

Denoël, M. (2017). On the identification of paedomorphic and overwintering larval newts based on cloacal shape: review and guidelines. Current Zoology, 63(2), 165-173. doi: 10.1093/cz/zow054

Denoël, M., \& Andreone, F. (2003). Trophic habits and aquatic microhabitat use in gilled immature, paedomorphic and metamorphic alpine newts (Triturus alpestris apuanus) in a pond in central Italy. Belgian Journal of Zoology, 133(2), 95-102.

Denoël, M., Drapeau, L., Oromi, N., \& Winandy, L. (2019a). The role of predation risk in metamorphosis versus behavioural avoidance: a sex-specific study in a facultative paedomorphic amphibian. Oecologia, 189, 637-645. doi: 10.1007/s00442-019-04362-8

Denoël, M., Drapeau, L., \& Winandy, L. (2019b). Reproductive fitness consequences of progenesis: sex-specific payoffs in safe and risky environments. Journal of Evolutionary Biology, 32(6), 629637. doi: $10.1111 /$ jeb.13449

Denoël, M., \& Ficetola, G. F. (2014). Heterochrony in a complex world: disentangling environmental processes of facultative paedomorphosis in an amphibian. Journal of Animal Ecology, 83(3), 606615. doi: 10.1111/1365-2656.12173

Denoël, M., \& Ficetola, G. F. (2015). Using kernels and ecological niche modeling to delineate conservation areas in an endangered patch-breeding phenotype. Ecological Applications, 25(7), 1922-1931. doi: 10.1890/14-1041.1 
Denoël, M., Hervant, F., Schabetsberger, R., \& Joly, P. (2002). Short- and long-term advantages of an alternative ontogenetic pathway. Biological Journal of the Linnean Society, 77(1), 105-112. doi: 10.1046/j.1095-8312.2002.00095.x

Denoël, M., Ivanović, A., Džukić, G., \& Kalezić, M. L. (2009). Sexual size dimorphism in the evolutionary context of facultative paedomorphosis: insights from European newts. $B M C$ Evolutionary Biology, 9(1), 278. doi: 10.1186/1471-2148-9-278

Denoël, M., \& Joly, P. (2000). Neoteny and progenesis as two heterochronic processes involved in paedomorphosis in Triturus alpestris (Amphibia: Caudata). Proceedings of the Royal Society B: Biological Sciences, 267(1451), 1481-1485. doi: 10.1098/rspb.2000.1168

Denoël, M., \& Joly, P. (2001). Adaptive significance of facultative paedomorphosis in Triturus alpestris (Amphibia, Caudata): resource partitioning in an alpine lake. Freshwater Biology, 46(10), 1387 1396. doi: $10.1046 / j .1365-2427.2001 .00762 . x$

Denoël, M., Joly, P., \& Whiteman, H. H. (2005). Evolutionary ecology of facultative paedomorphosis in newts and salamanders. Biological Reviews of the Cambridge Philosophical Society, 80(4), 663 671. doi: $10.1017 / \mathrm{S} 1464793105006858$

Denoël, M., Schabetsberger, R., \& Joly, P. (2004). Trophic specialisations in alternative heterochronic morphs. Die Naturwissenschaften, 91(2), 81-84. doi: 10.1007/s00114-003-0492-6

Denoël, M., Whiteman, H. H., \& Wissinger, S. A. (2007). Foraging tactics in alternative heterochronic salamander morphs: trophic quality of ponds matters more than water permanency. Freshwater Biology, 52(9), 1667-1676. doi: 10.1111/j.1365-2427.2007.01793.x

Denoël, M., \& Winandy, L. (2015). The importance of phenotypic diversity in conservation: Resilience of palmate newt morphotypes after fish removal in Larzac ponds (France). Biological Conservation, 192, 402-408. doi: 10.1016/j.biocon.2015.10.018

Erwin, D. H. (2015). Novelty and innovation in the history of life. Current Biology, 25(19), R930-R940. doi: 10.1016/j.cub.2015.08.019

Fabre, A., Bardua, C., Bon, M., Clavel, J., Felice, R. N., Streicher, J. W., ... Goswami, A. (2020). Metamorphosis shapes cranial diversity and rate of evolution in salamanders. Nature Ecology \& Evolution, 4, 1129-1140. doi: 10.1038/s41559-020-1225-3

Fages, A. (2004). La quête de l'eau. Du Néolithique... à nos jours. Millau: Los Adralhans.

Francis, T. B., \& Schindler, D. E. (2009). Shoreline urbanization reduces terrestrial insect subsidies to fishes in North American lakes. Oikos, 118(12), 1872-1882. doi: 10.1111/j.16000706.2009.17723.x

Frédérich, B., Lehanse, O., Vandewalle, P., \& Lepoint, G. (2010). Trophic niche width, shift, and specialization of Dascyllus aruanus in Toliara lagoon, Madagascar. Copeia, 2010(2), 218-226. doi: 10.1643/CE-09-031

Frédérich, B., Santini, F., Konow, N., Schnitzler, J., Lecchini, D., \& Alfaro, M. E. (2017). Body shape convergence driven by small size optimum in marine angelfishes. Biology Letters, 13(6), 20170154. doi: $10.1098 /$ rsbl.2017.0154

Fry, B., \& Davis, J. (2015). Rescaling stable isotope data for standardized evaluations of food webs and species niches. Marine Ecology Progress Series, 528, 7-17. doi: 10.3354/meps11293

Gabrion, J. (1976). La néoténie chez Triturus helveticus Raz. Etude morphofonctionnelle de la fonction thyroidienne. $\mathrm{PhD}$ thesis, Université des Sciences et Techniques du Languedoc, Montpellier.

Gabrion, J., Sentein, P., \& Gabrion, C. (1977). Les populations néoténiques de Triturus helveticus des Causses et du Bas-Languedoc I. Répartition et caractéristiques. La Terre et La Vie, 31, 489-506.

Gao, K., \& Shubin, N. H. (2001). Late Jurassic salamanders from northern China. Nature, 410, 574 577. doi: $10.1038 / 35069051$ 
Gould, S. (1977). Ontogeny and phylogeny. Cambridge, MA, USA: Belknap Press of Harvard University Press.

Hanken, J., \& Wake, D. B. (1993). Miniaturization of body size: Organismal consequences and evolutionary significance. Annual Review of Ecology and Systematics, 24(1), 501-519. doi: 10.1146/annurev.es.24.110193.002441

Jackson, A. L., Inger, R., Parnell, A. C., \& Bearhop, S. (2011). Comparing isotopic niche widths among and within communities: SIBER - Stable Isotope Bayesian Ellipses in R. Journal of Animal Ecology, 80(3), 595-602. doi: 10.1111/j.1365-2656.2011.01806.x

Jakob, E. M., Marshal, S. D., \& Uetz, G. W. (1996). Estimating fitness: A comparison of body condition indices. Oikos, 77(1), 61-67. doi: 10.2307/3545585

Joly, P. (1987). Le régime alimentaire des amphibiens méthodes d'étude. Alytes, 6 (1), 11-17.

Kalezić, M. L., Cvetković, D., Djorović, A., \& Džukić, G. (1996). Alternative life-history pathways: Paedomorphosis and adult fitness in European newts (Triturus vulgaris and T. alpestris). Journal of Zoological Systematics and Evolutionary Research, 34(1), 1-7. doi: 10.1111/j.14390469.1996.tb00804.x

Kon, T., \& Yoshino, T. (2002). Extremely early maturity found in Okinawan gobioid fishes. Ichthyological Research, 49(3), 224-228. doi: 10.1007/s102280200031

Korn, D. (1995). Impact of environmental perturbations on heterochronic developments in Paleozoic ammonoids. In K. J. McNamara (Ed.), Evolutionary change and heterochrony (pp. 245-260). Chichester: John Wiley \& Sons Ltd.

Lackey, A., Moore, M. P., Doyle, J., Gerlanc, N., Hagan, A., Geile, M., ... Whiteman, H. H. (2019). Lifetime fitness, sex-specific life history, and the maintenance of a polyphenism. The American Naturalist, 194(2), 230-245. doi: 10.1086/704156

Lauder, G. V., \& Reilly, S. M. (1994). Amphibian feeding behavior: comparative biomechanics and evolution. In V. Bels, M. Chardon, \& P. Vanderwalle (Eds.), Advances in comparative and environmental physiology, vol 18 (pp. 163-195). doi: 10.1007/978-3-642-57906-6_7

Lauder, G. V., \& Shaffer, B. H. (1993). Design of feeding systems in aquatic vertebrates: major patterns and their evolutionary interpretations. In J. Hanken \& B. K. Hall (Eds.), The Skull, Vol. 3: Functional and evolutionary mechanisms (pp. 113-149). Chicago, Illinois, USA: Chicago University Press.

Laudet, V. (2011). The origins and evolution of vertebrate metamorphosis. Current Biology, 21(18), R726-R737. doi: 10.1016/j.cub.2011.07.030

Lefebvre, F., \& Poulin, R. (2005). Progenesis in digenean trematodes: a taxonomic and synthetic overview of species reproducing in their second intermediate hosts. Parasitology, 130(6), 587605. doi: 10.1017/S0031182004007103

Lejeune, B., Sturaro, N., Lepoint, G., \& Denoël, M. (2018). Facultative paedomorphosis as a mechanism promoting intraspecific niche differentiation. Oikos, 127(3), 427-439. doi: 10.1111/oik.04714

Levis, N. A., de la Serna Buzón, S., \& Pfennig, D. W. (2015). An inducible offense: Carnivore morph tadpoles induced by tadpole carnivory. Ecology and Evolution, 5(7), 1405-1411. doi: 10.1002/ece3.1448

Long, J. A. (1990). Heterochrony and the origin of tetrapods. Lethaia, 23(2), 157-166. doi: 10.1111/j.1502-3931.1990.tb01357.x

Mathiron, A. G. E., Lena, J. P., Baouch, S., \& Denoël, M. (2017). The 'male escape hypothesis': Sexbiased metamorphosis in response to climatic drivers in a facultatively paedomorphic amphibian. Proceedings of the Royal Society B: Biological Sciences, 284(1853), 20170176. doi: 10.1098/rspb.2017.0176 
McKinney, M. L., \& McNamara, K. J. (1991). Heterochrony: the evolution of ontogeny. doi: 10.1007/978-1-4757-0773-1

McNamara, K. J. (1997). Shapes of time: the evolution of growth and development. Baltimore, MD: Johns Hopkins University Press.

McNamara, K. J. (2012). Heterochrony: the evolution of development. Evolution: Education and Outreach, 5(2), 203-218. doi: 10.1007/s12052-012-0420-3

Moczek, A. P., Sultan, S., Foster, S., Ledon-Rettig, C., Dworkin, I., Nijhout, H. F., ... Pfennig, D. W. (2011). The role of developmental plasticity in evolutionary innovation. Proceedings of the Royal Society B: Biological Sciences, 278(1719), 2705-2713. doi: 10.1098/rspb.2011.0971

Newsome, S. D., Martinez del Rio, C., Bearhop, S., \& Phillips, D. L. (2007). A niche for isotope ecology. Frontiers in Ecology and the Environment, 5(8), 429-436. doi: 10.1890/060150.01

Nosil, P., \& Reimchen, T. E. (2005). Ecological opportunity and levels of morphological variance within freshwater stickleback populations. Biological Journal of the Linnean Society, 86(3), 297-308. doi: 10.1111/j.1095-8312.2005.00517.x

Oromi, N., Michaux, J., \& Denoël, M. (2016). High gene flow between alternative morphs and the evolutionary persistence of facultative paedomorphosis. Scientific Reports, 6, 32046. doi: $10.1038 / \operatorname{srep} 32046$

Pfennig, D. W. (1992). Proximate and functional causes of polyphenism in an anuran tadpole. Functional Ecology, 6(2), 167-174. doi: 10.2307/2389751

Pinheiro, J., Bates, D., DebRoy, S., Sarkar, D., \& Team, R. C. (2018). nlme: Linear and nonlinear mixed effects models. $R$ Package Version 3.1-137, p. https://CRAN.R-project.org/package=nlme.

R Core Team. (2018). R: A language and environment for statistical computing. R Foundation for Statistical Computing, Vienna, Austria.

Recknagel, H., Hooker, O. E., Adams, C. E., \& Elmer, K. R. (2017). Ecosystem size predicts ecomorphological variability in a postglacial diversification. Ecology and Evolution, 7(15), 55605570. doi: 10.1002/ece3.3013

Ryan, T. J., \& Semlitsch, R. D. (1998). Intraspecific heterochrony and life history evolution: Decoupling somatic and sexual development in facultatively paedomorphic salamander. Proceedings of the National Academy of Sciences of the USA, 95, 5643-5648. doi: 10.1073/pnas.95.10.5643

Schabetsberger, R. (1994). Gastric evacuation rates of adult and larval alpine newts (Triturus alpestris) under laboratory and field conditions. Freshwater Biology, 31(2), 143-151. doi: 10.1111/j.13652427.1994.tb00848.x

Schmidt, P. S., Bertness, M. D., \& Rand, D. M. (2000). Environmental heterogeneity and balancing selection in the acorn barnacle Semibalanus balanoides. Proceedings of the Royal Society B: Biological Sciences, 267(1441), 379-384. doi: 10.1098/rspb.2000.1012

Semlitsch, R. D. (1987). Paedomorphosis in Ambystoma talpoideum: effects of density, food, and pond drying. Ecology, 68(4), 994-1002. doi: 10.2307/1938370

Shannon, C. E. (1948). A mathematical theory of communication. The Bell System Technical Journal, 27, 379-423. doi: $10.1145 / 584091.584093$

Simpson, G. G. (1944). Tempo and mode in evolution. New York: Columbia University Press.

Skulason, S., \& Smith, T. B. (1995). Resource polymorphisms in vertebrates. Trends in Ecology \& Evolution, 10(9), 366-370. doi: 10.1016/S0169-5347(00)89135-1

Smith, T. B., \& Skúlason, S. (1996). Evolutionary significance of resource polymorphisms in fishes, amphibians, and birds. Annual Review of Ecology and Systematics, 27(1), 111-133. doi: 10.1146/annurev.ecolsys.27.1.111

Snyder, J., \& Bretsky, P. W. (1971). Life habits of diminutive bivalve molluses in the Maquoteka 
formation (Upper Ordovician). American Journal of Science, 271(3), 227-251. doi: 10.2475/ajs.271.3.227

Stock, B. C., \& Semmens, B. X. (2016). MixSIAR GUI User Manual, version 1.0.

Struck, T. H., Golombek, A., Weigert, A., Franke, F. A., Westheide, W., Purschke, G., ... Halanych, K. M. (2015). The evolution of annelids reveals two adaptive routes to the interstitial realm. Current Biology, 25(15), 1993-1999. doi: 10.1016/j.cub.2015.06.007

Vignoli, L., Luiselli, L., \& Bologna, M. A. (2009). Dietary patterns and overlap in an amphibian assemblage at a pond in mediterranean central Italy. Vie et Milieu-Life and Environment, 59(1), $47-57$.

Wellborn, G. A., \& Langerhans, R. B. (2015). Ecological opportunity and the adaptive diversification of lineages. Ecology and Evolution, 5(1), 176-195. doi: 10.1002/ece3.1347

Werner, E. E., \& Gilliam, J. F. (1984). The ontogenetic niche and species interactions in size-structured populations. Annual Review of Ecology and Systematics, 15, 393-425.

West-Eberhard, M. J. (1989). Phenotypic plasticity and the origins of diversity. Annual Review of Ecology and Systematics, 20, 249-278. doi: 10.1146/annurev.es.20.110189.001341

West-Eberhard, M. J. (2003). Developmental plasticity and evolution. Oxford, UK: Oxford University Press.

Westheide, W. (1987). Progenesis as a principle in meiofauna evolution. Journal of Natural History, 21(4), 843-854. doi: 10.1080/00222938700770501

Whiteman, H. H. (1994). Evolution of facultative paedomorphosis in Salamanders. The Quarterly Review of Biology, 69(2), 205-221. doi: 10.1086/418540

Whiteman, H. H. (1997). Maintenance of polymorphism promoted by sex-specific fitness payoffs. Evolution, 51(6), 2039-2044. doi: 10.2307/2411026

Whiteman, H. H., Wissinger, S. A., \& Brown, W. S. (1996). Growth and foraging consequences of facultative paedomorphosis in the tiger salamander Ambystoma tigrinum nebulosum. Evolutionary Ecology, 10(4), 433-446. doi: 10.1007/BF01237728

Whiteman, H. H., Wissinger, S. A., Denoël, M., Mecklin, C. J., Gerlanc, N. M., \& Gutrich, J. J. (2012). Larval growth in polyphenic salamanders: making the best of a bad lot. Oecologia, 168(1), 109118. doi: 10.1007/s00442-011-2076-z

Wilbur, H. M., \& Collins, J. P. (1973). Ecological aspects of amphibian metamorphosis. Science, 182(4119), 1305-1314. doi: 10.1126/science.182.4119.1305

Wilson, D. S. (1975). The adequacy of body size as a niche difference. The American Naturalist, 109(970), 769-784. doi: 10.1086/283042

Wimberger, P. H. (1994). Trophic polymorphisms, plasticity, and speciation in vertebrates. In D. J. Stouder, K. Fresh, \& R. J. Feller (Eds.), Theory and application in fish feeding ecology (pp. 1943).

Winandy, L., Colin, M., \& Denoël, M. (2016). Temporal habitat shift of a polymorphic newt species under predation risk. Behavioral Ecology, 27(4), 1025-1032. doi: 10.1093/beheco/arw008

Woodward, G., \& Hildrew, A. G. (2002). Body-size determinants of niche overlap and intraguild predation within a complex food web. Journal of Animal Ecology, 71(6), 1063-1074. doi: 10.1046/j.1365-2656.2002.00669.x 


\section{SUPPORTING INFORMATION}

Additional supporting information may be found in the online version of this article.

Appendix S1 Details on stable isotopes processing, rescaling method and mixing models

Figure S1 Typical pond hosting paedomorphic and metamorphic palmate newts.

Figure S2 SEA в of paedomorphs and metamorphs of each pond.

Table S1 Characteristics of the studied ponds.

Table S2 Sample sizes for each type of analysis.

Table S3 Effect of SVL, phenotype, sex and their interactions on C:N ratio in newts skin tissue.

Table S4 Effect of phenotype, sex, pond and their interactions on SVL and BC.

Table S5 Post hoc pairwise tests of SVL and BC differences.

Table S6 Post hoc pairwise tests of $H^{\prime}$ among ponds.

Table S7 Rescaled isotope values and niche metrics of paedomorphs and metamorphs.

Table S8 Pairwise comparisons of $\mathrm{CD}_{\mathrm{B}}, \mathrm{SNS}_{\mathrm{B}}$ and $\mathrm{PC}_{\mathrm{B}}$.

Table S9 Effect SVL, phenotype, sex and their interactions on $\Delta^{13} \mathrm{C}$ and $\Delta^{15} \mathrm{~N}$ of newts.

Table S10 Effect of BSR, sex, pond depth and their interactions on ISO-DIST.

Table S11 Effects of phenotype, sex and their interaction on the diet of palmate newts.

Table S12 SIMPER analysis of diet composition of both phenotypes in each pond.

Table S13 Results of stable isotope mixing models before a posteriori grouping. 